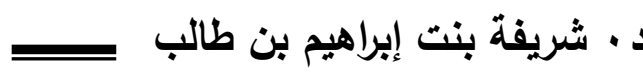

\title{
الأبعاد الثقافية
}

\section{بين شعر الحماسة وفن الثيلات}

د ـ شريفة بنت إبراهيم بن طالب (")

المقدمة :

الحمد الله وحده، والصلاة والسلام على من لانبي بعده، ويعد:

فإن الارتباط بين الماضي والحاضر وثثي ممتد، والتواشج والتشابه بين فنون الأدب وأجناسه ظاهر وبين، وكثثر من الأنواع الأدبية تتطور، وتنتوالد، وتتداخل فيما بينها، بما بطور الأدب ويجدده، وقد قال الثاعر الأول: ما أرانا نقول إلا معارا ومعادا من قولنا مكرور

وقديما ازدهرت وانتشرت قصائد الحماسـة، حتى قيل إن موضـوع الحماسـة

غلب كل موضوع، وهو أكبر باب في المجموعات الشعرية، وأول باب في كتاب أبي تمام، وبها أسمى كتابه، وأطلقت الحماسة على كثير من المجموعات الثعرية كحماسة البحتري وابن الثجري . واليوم نجد نوعا من الثعر الشعبي يزدهر ازدهارا كبيرا، وله من سمات شعر

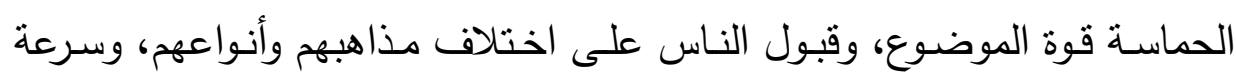

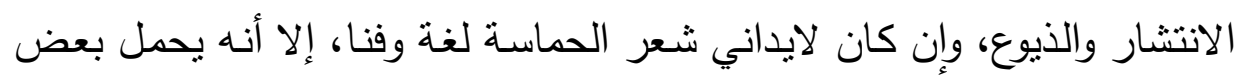
سماته؛ وهو ما بسمى "فن الشيلات"، فلا تجد موضوعا إلا وفيه شيلة، ولا قبيلة، ولا حتى اسم، إلا ويكتب ويغنى ويردد باسمه شيلة.

(*) أستاذ مساعد في الأدب والنقد قسم اللغة العربية، كلبة التربية بالدلم جامعة الأمير سطام ابن عبد العزيز بالخرج، المملكة العربية السعودية. 
ولايكاد أحد ينكر انتشار الشيلات واكتساحها المشهر الثقافي، ومزاحتها

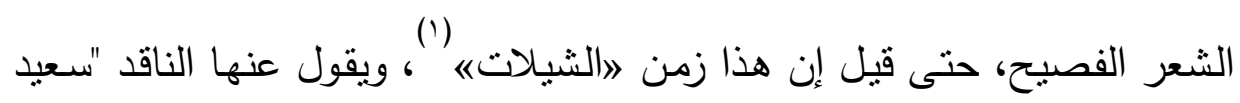

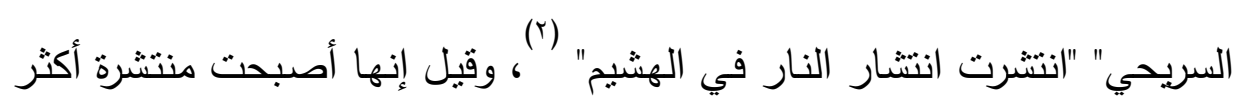

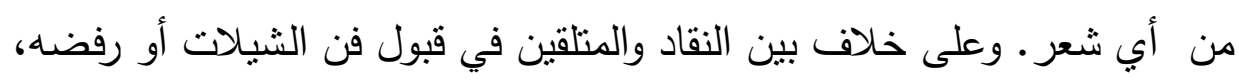

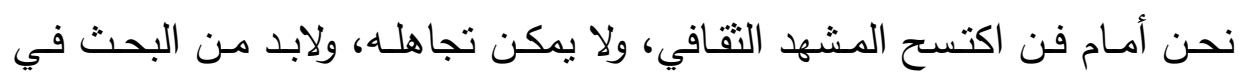

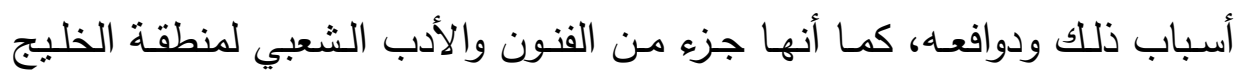

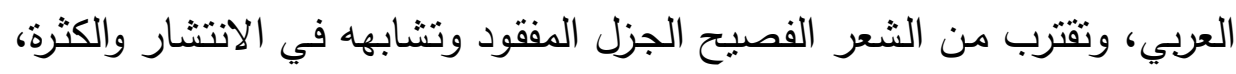

وتعلق الناس بها، وتلبيتها لحاجتهم الفنية والغنائية.

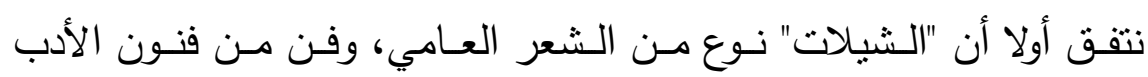

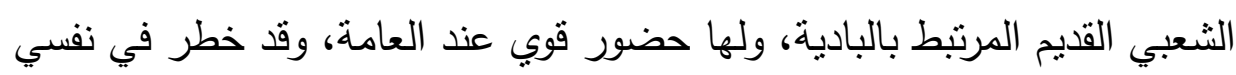

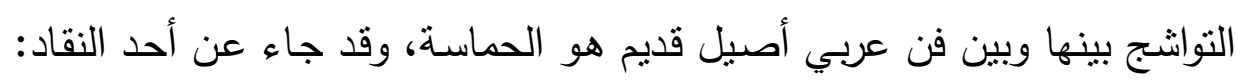

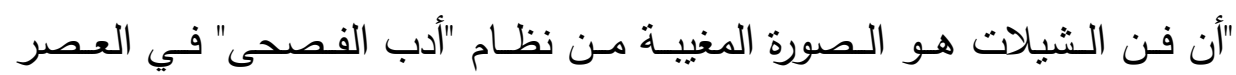
الجاهلي" "(") حيث تجمعهما بعض السمات، ونلمح فيه من سمات شعر الحماسة-

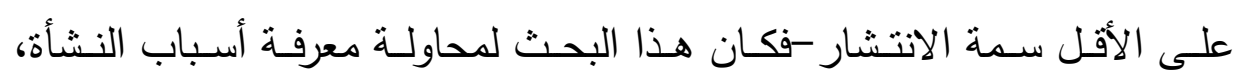
وظروف البدايات، وما علاقة انحسار شعر الحماسة الفصيح بذيوع الثيلات ؟

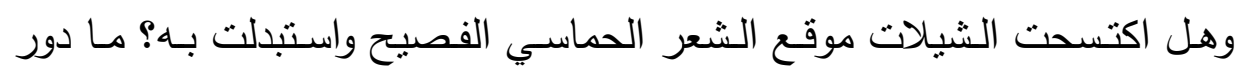

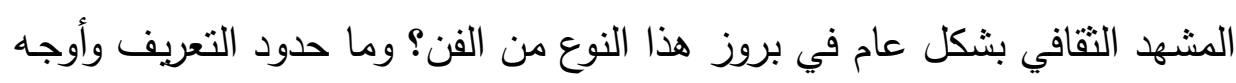

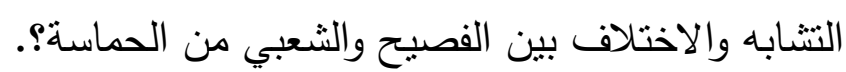

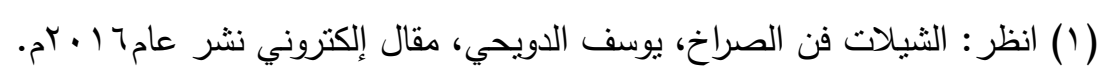

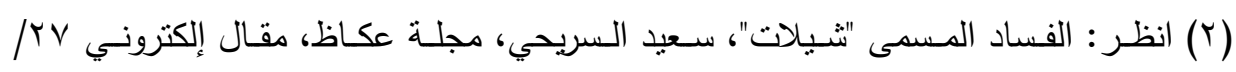
أغسطس / عام Vا • بام. (ץ) انظر : مقال على الثبكة الإلكترونية، بعنوان: من أين جاءت الثيلات ؟، سمير الضامر،

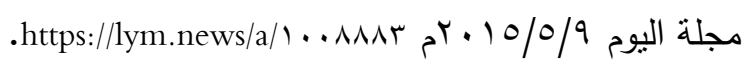




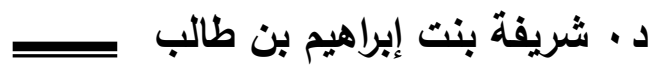

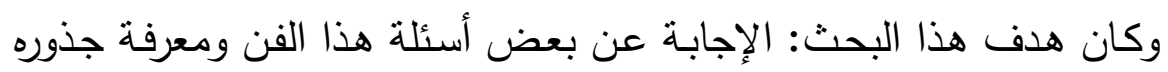

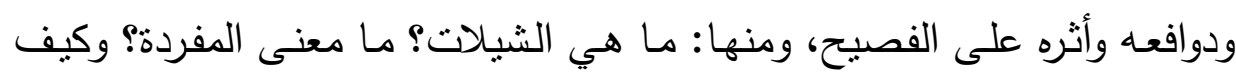

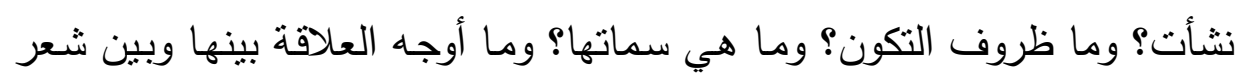
الحماسة المعروف والأصيل في الثقافة العربية؟ إن كثرت الثيلات وانتشارها يغري كذلك بالبحث في بعدها الفني والنفسي،

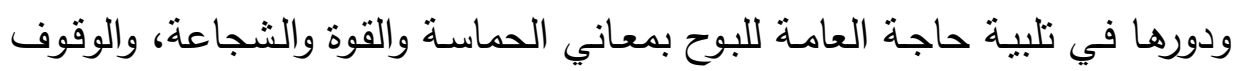

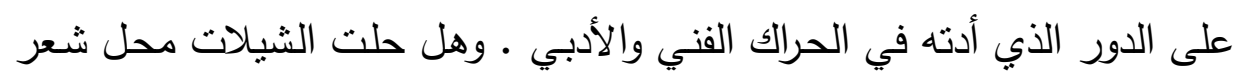
الحماسة؟ وهل هي مظهر جيد لنقافة العصر؟.

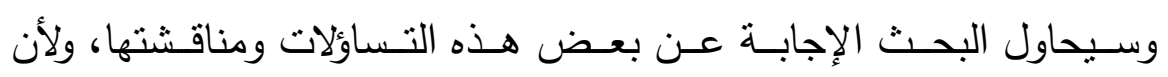

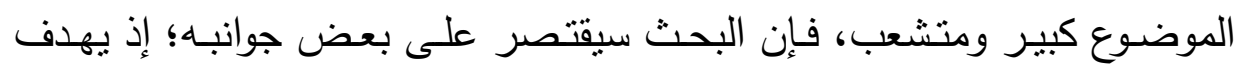
البحث إلى الوقوف على هذا الفن والبحث عن جذوره، وعلاقته بالتراث الأدبي والثعر العربي الفصيح، وستركز الدراسة على محورين: التعريف، وأوجه التشابه والاختلاف. 
جذور الثيلات ونثأتها وموقعها من المشهـ الثقافي والأدبي:

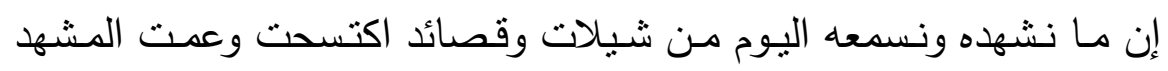

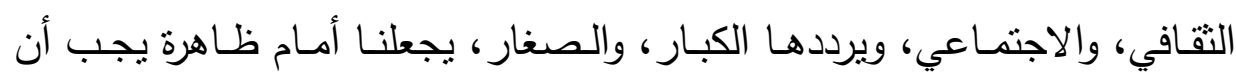

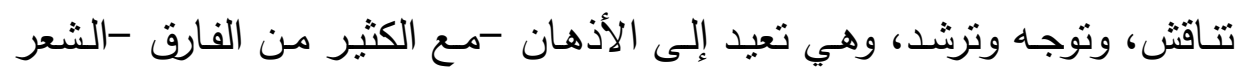

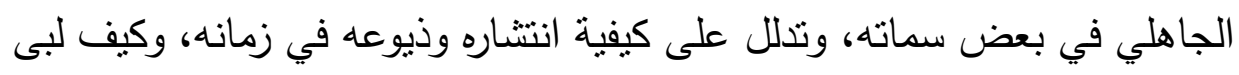

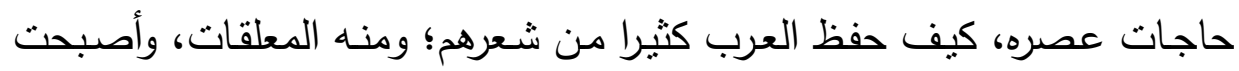

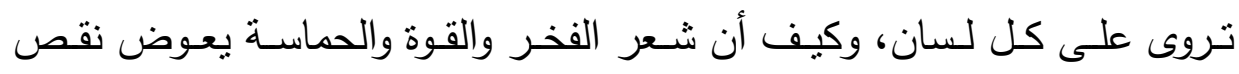

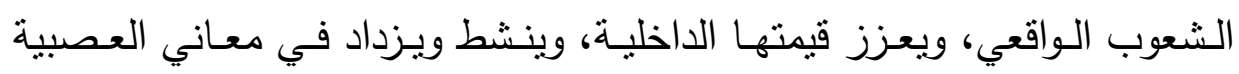

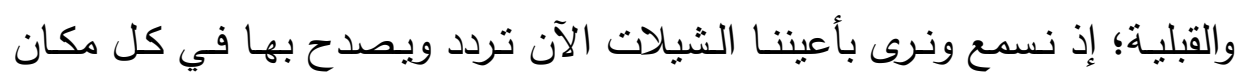

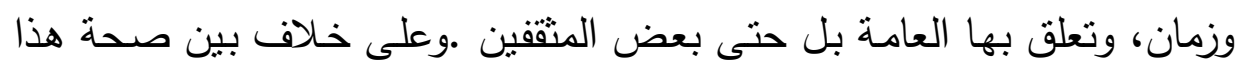

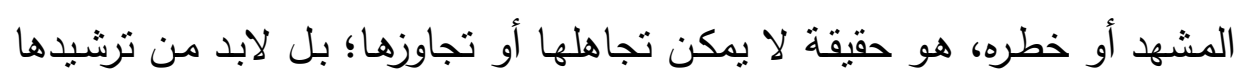
وتوجيهها بما يخدم الأدب الفصيح ويعززه.

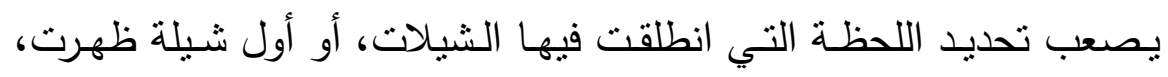

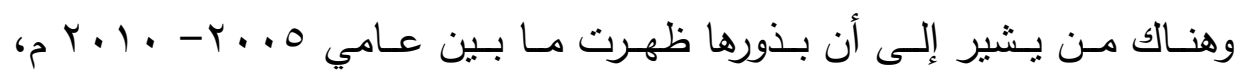

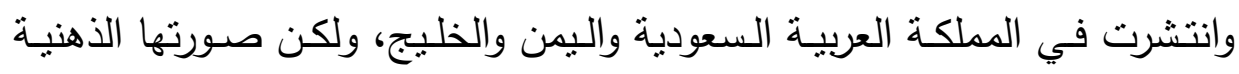

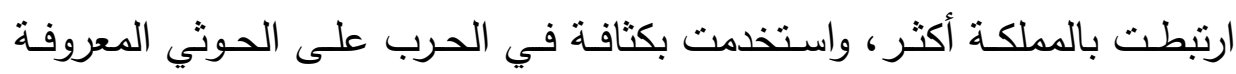

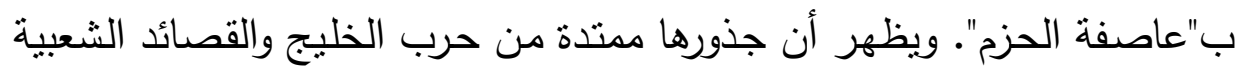

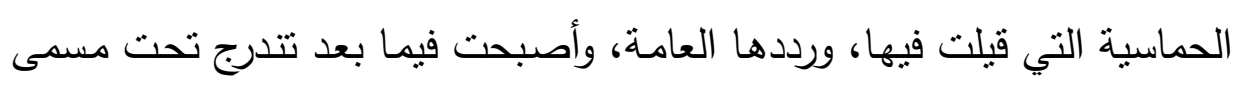

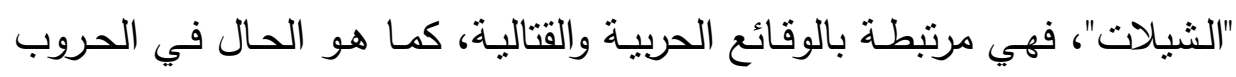




\section{د ـ شريفة بنت إبراهيم بن طالب سل}

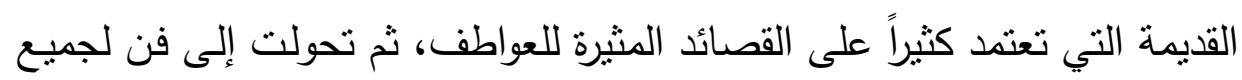

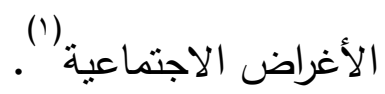

وعند البحث عن أصول الثيلات، نجد من يقول أن الأصل في (الثيلاته)،

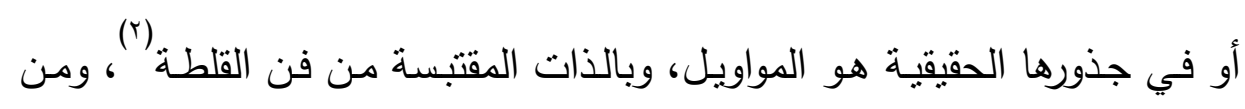

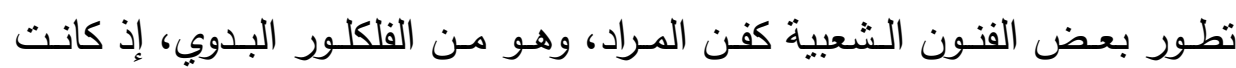

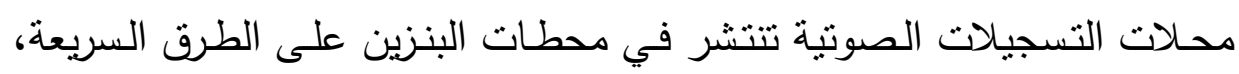

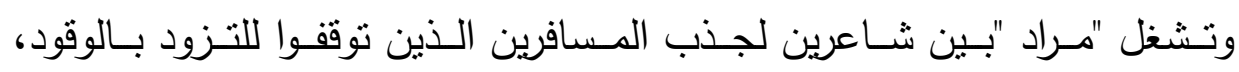

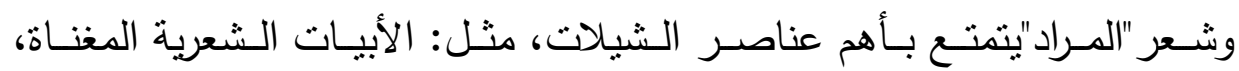

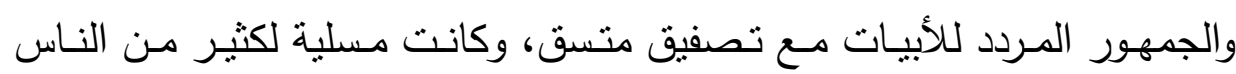
ويقطعون الطرق الطويلة بالاستمتاع بها (r). وهناك من يقول: إن الشيلة ليست بأكثر من هجين من فن مواويل القلطة، (₹) وفن الأناشيد الإسلامية، وهي شكل غنائي وليست فنا مستقلا.

( (1) انظر : الشيلات لون فني شـعبي مستحدث، عبد الرحمن الشقير ، مجلـة الاقتصادية،

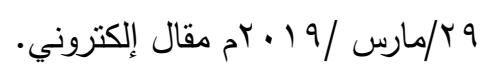

https://www.aleqt.com/r.19/.r/rq/article_l ov_..01.html

(ץ) انظر : "الثيلات".. أصوات تتجمل بالحيل النقنية، فهد زيدان، مقال إلكتروني، مجلة اليوم

$$
\text { . } r \cdot 1 v / \varepsilon / 9
$$

https://www.al-madina.com/article/० ४৭^/9

(ץ) انظر : الشيلات لون فني شعبي مستحدث، عبد الرحمن الشقير ، مجلـة الاقتصادية،

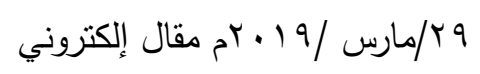

.html https://www.aleqt.com/r.19/.r/ $9 /$ article_10 . .01

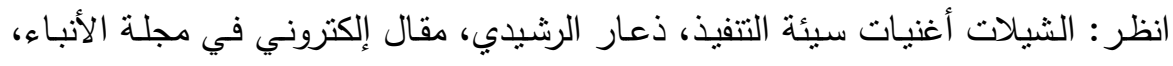

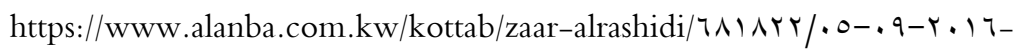

$$
\cdot r^{2} \cdot 17 / 9 / 0
$$


والشيلات شديدة الشبه بالأناشيد الإسـامية، غير أن الفارق بين 》الثيلةها

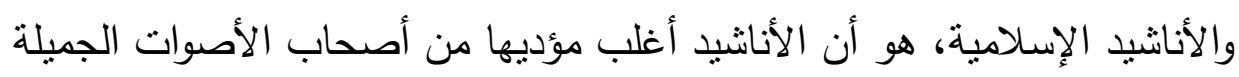
والمميزة، أما الثيلات فلا تعتمد على جمال الصوت، وإندانيد إنما تعتمد على القوة والنبرة

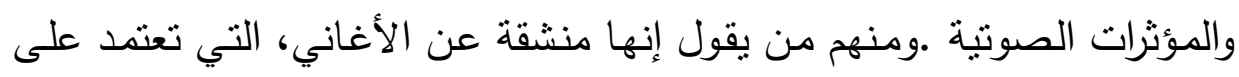

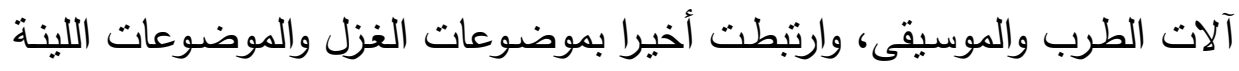

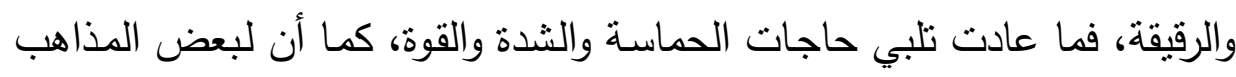
والفقهاء موقفا صارما منها ' '.

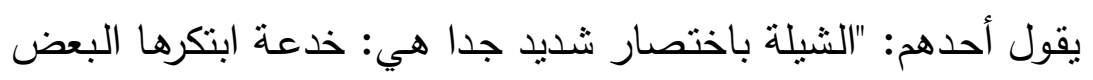

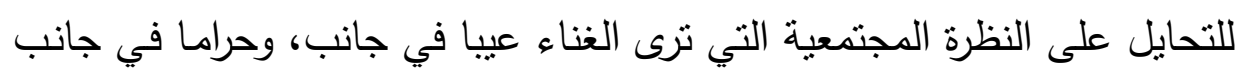

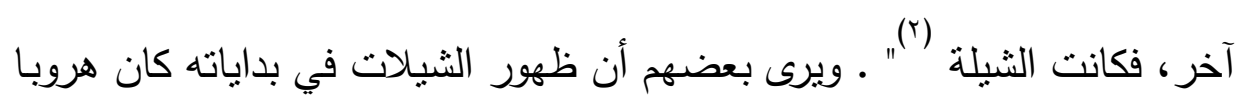

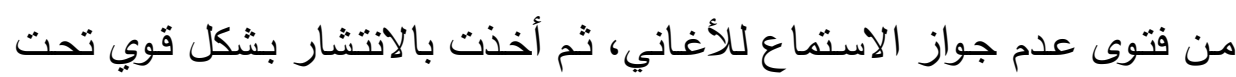
عباءة الجواز لخلوها من المعازف ' .

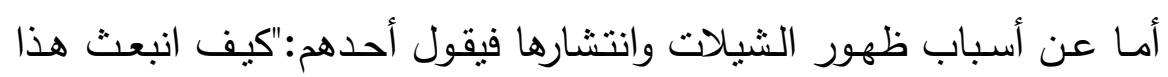

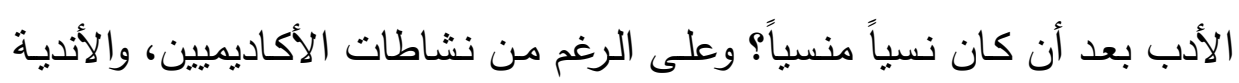

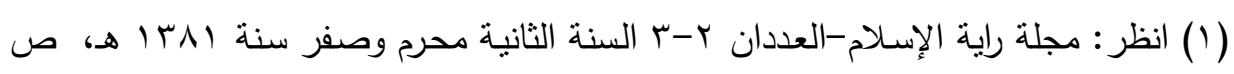

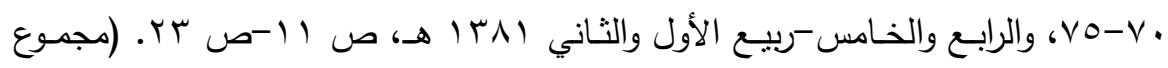

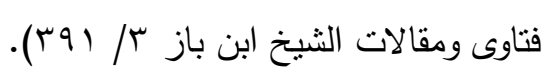

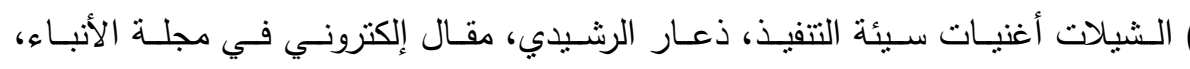

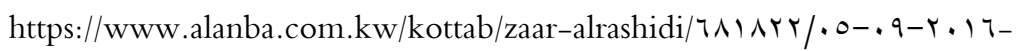

$$
\text { . } r \cdot 17 / 9 / 0
$$

(ץ) انظر :》الثيلاته فن شعبي موروث أم 》دغدغةه عاطفية؟ عبد الرحمن الصالحي، مقال

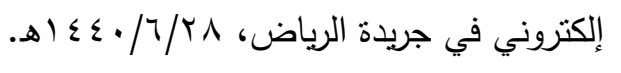

https://www.alriyadh.com/IVs/ Vv. 


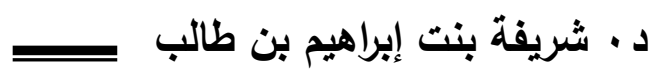

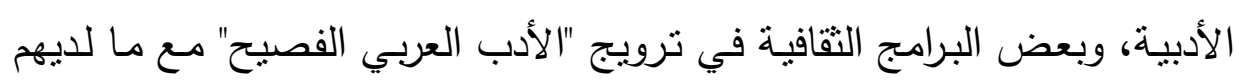

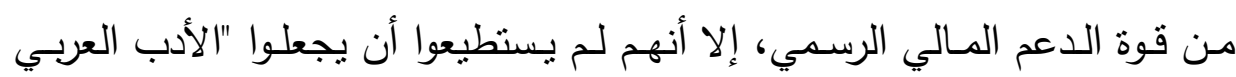
الفصيح" خطابـاً ثقافياً شـعبياً! ولم يستطيعوا أن يفكوا شفرة الذهنيـة الاجتماعيـة لتنقبل أدب الفصحى كما هو في كتب التراث القديمة! ثم يقول:والسبب الرئيس في نظري أن مروجي "أدب الفصحى" نسوا أو تتاسوا أنه أدب شعبي، قائم في بنيته على الميثيولوجيا، والعصبية القبلية، ومرتبط بالحروب، والمرأة، والناقة!. وحولوا ذلك الأدب من نظامهـ الشعبي، إلى أدب خاضِِ لمعايير نقدية تارةً، ولاتجاهـات دينية واجتماعية تارة أخرى، ولاتجاهات فنية بحتة، مما أبعد هذا الأدب عن تلقي العامة، وانصرفوا لكل ما هو شعبي متاح لم يُحتوَ من أي جهة رسمية" "' كما أن الموسيقى والمعازف حرام في الثرع، والثيلات تحايلت على المحرم وعلى العيب

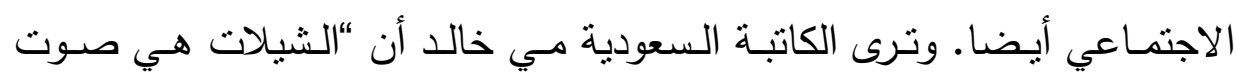
الشارع في السعودية الآن"؛ وذلك لارتباطها الوثيق بالحيـاة المعيشية للمـواطن البسيط، وتكلفتها غير المرتفعة، وتتوع مواضيعها على خلاف الأغاني التقليدية.

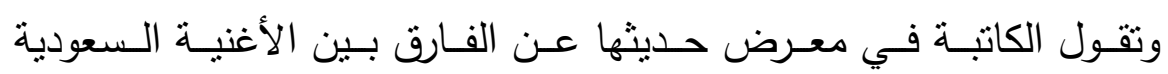
و "الثيلات"، إن “الأغنية السعودية أرستقراطية؛ فأثـهر شعراء الأغنية السعودية وأغزرهم إنتاجًا أمراء.. الأمير خالد الفيصل، وبدر بن عبد المحسن، وعبد الهه اله الفيصل.. أو وجهاء منل سعود الثربتلي وغيره ".

وتضيف مي خالد، في مقال نشرته صحيفة “عكاظ” السعودية اليوم الأربعاء، أن “شعراء الشيلات مواطنون بسطاء، وبعضهم من الشعراء القدامى في الجزيرة العربية ممن أوشكت قصائدهم أن تتدثز دون توثيقها. وهذه وظيفة ثقافية عظيمة

(1) انظر : من أين جاءت الشيلات ؟، سمير الضامر ، مقال على الشبكة الإكترونية، مجلة

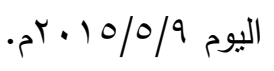

https://lym.news/a// . . ^^^ץ 


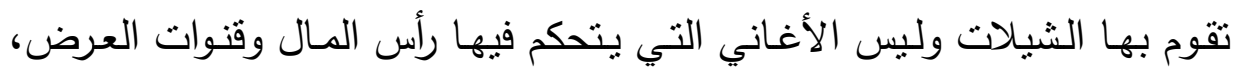

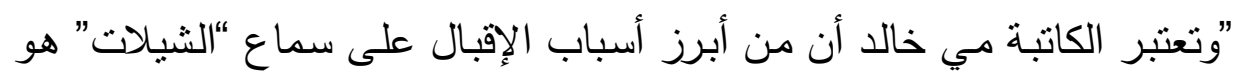

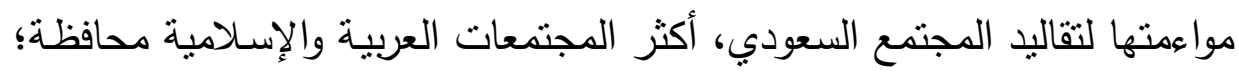

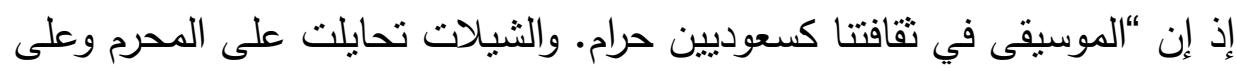

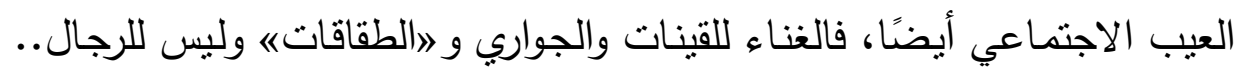
(') بينما الثيلات الحماسية غير المائعة للرجال اطوال الثواربه ' .

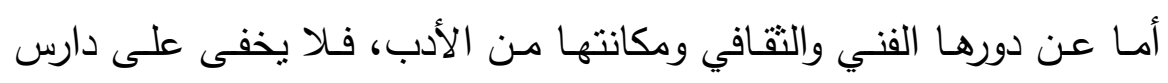

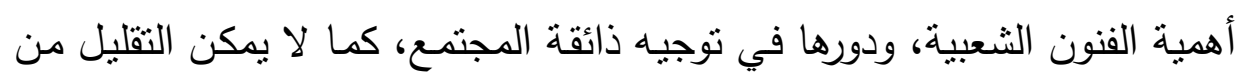

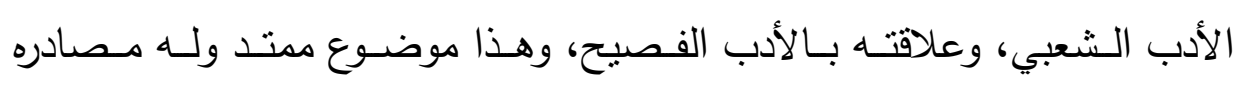
ومضانه. * *

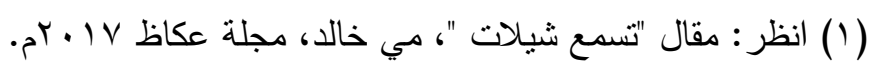
https://www.okaz.com.sa/articles/na/lorv^rv 


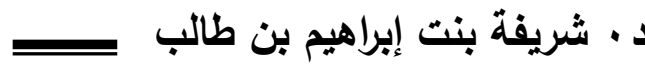

المبحث الأول

التعريف

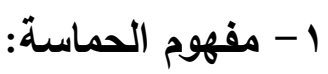

تدور معاني الحماسة على الشجاعة، والثدة، والتشدّد، والصلابة، والقتال،

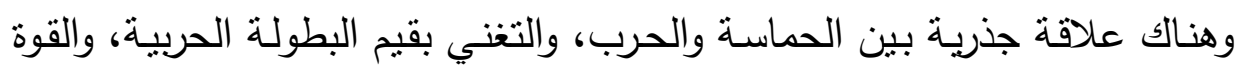
العسكرية، والثقة بالنفس والفتوة.

وجاء في صحاح الجوهري: "الأحمس الثديد الصلب في الدين، والقتال، وقد

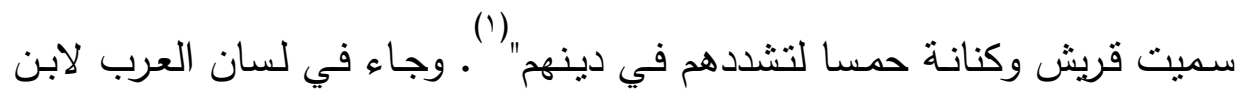
منظور : "الحماسة: الشدة، حمس الشر واشتخ، وتحمس التشدد، والسنة الحمساء

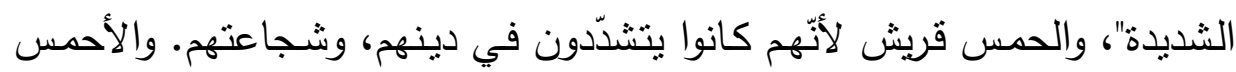

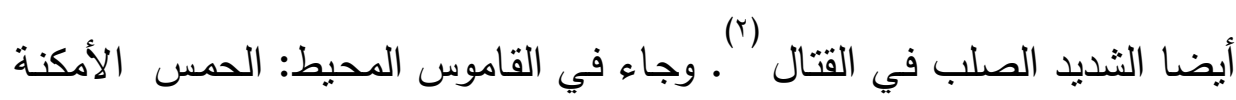

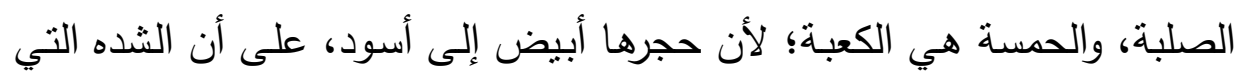

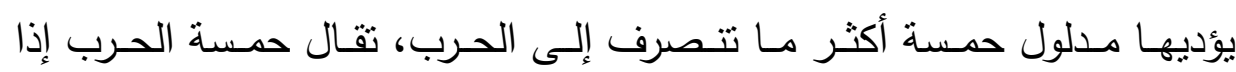
اشتدت، بل تشمل الثدة في كل شيء، إن الثجاعة والحماسـة والبسالة بمعنى

واحد (ّ) . وفي تاج العروس للزبيدي: "الحماسه هي الثجاعه والمنع والمحاربه" (؛) .

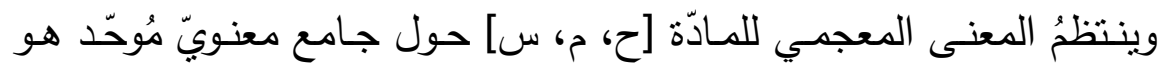

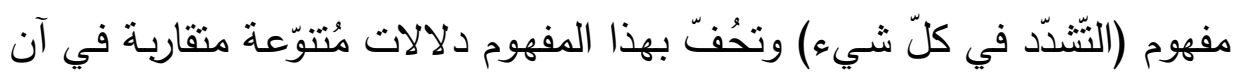

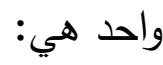

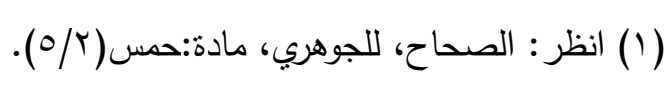

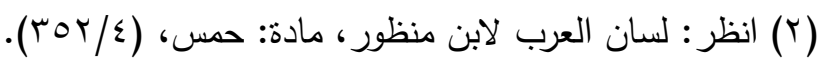

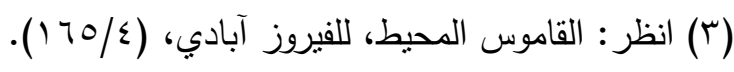

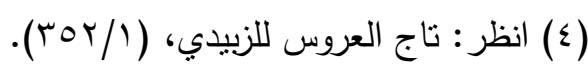

$-1 \cdot 0-$ 


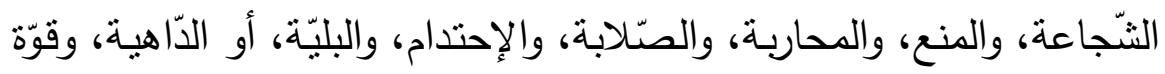

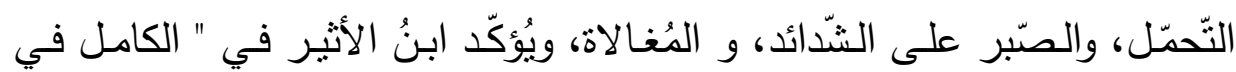

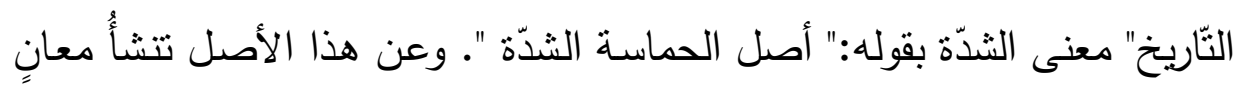

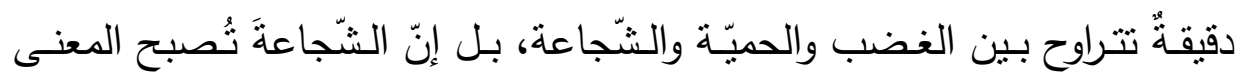

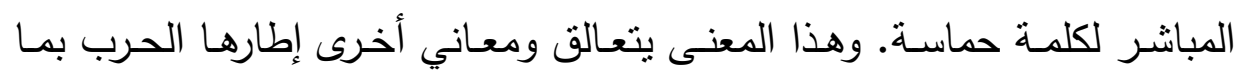

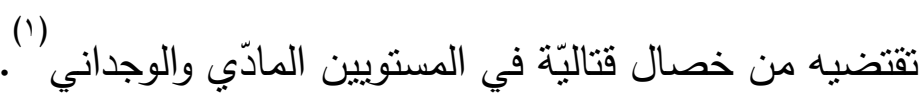
شعر الحماسة:

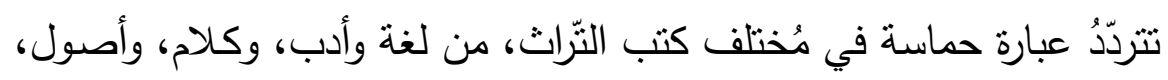

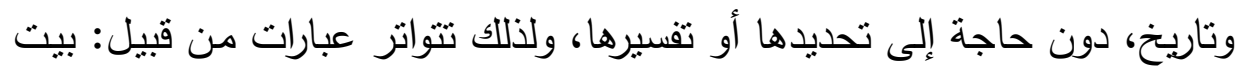

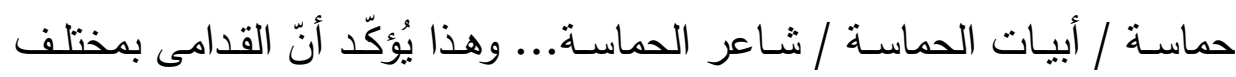
مشاغلهم لم يبدُ لهم معنى الحماسة مُبهما ملتبسا.

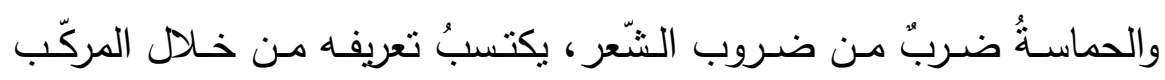

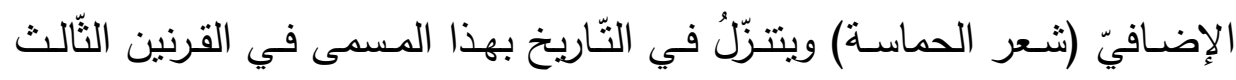

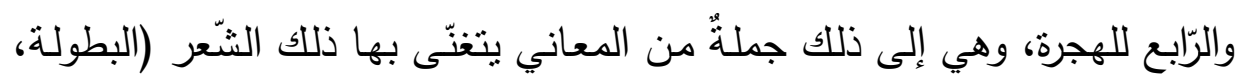

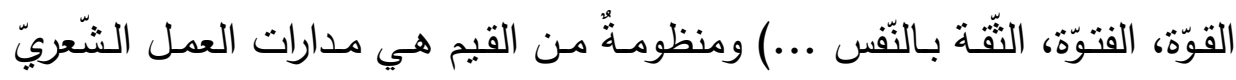

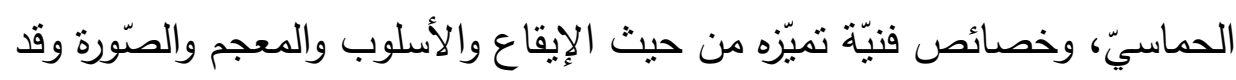

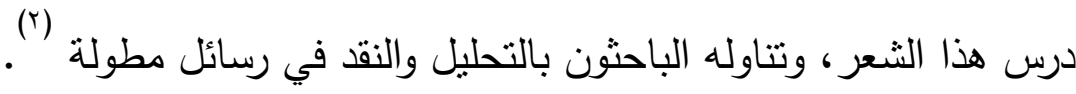

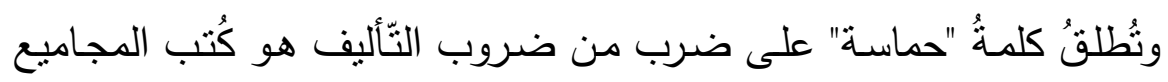

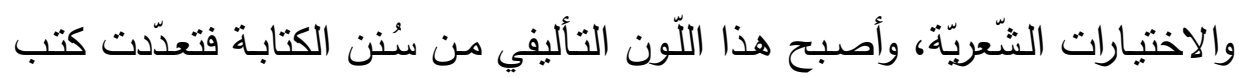

$$
\begin{aligned}
& \text { (1) انظر : الخصائص الأسلوبية في شعر الحماسة بين أبي تمام والبحتري (شعر الحرب الهُب } \\
& \text { والفخر أنموذجا)، أحمد النهمي، رسالة دكتوراه مخطوطة . }
\end{aligned}
$$

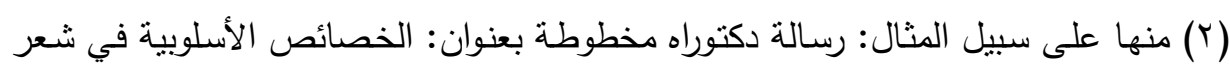

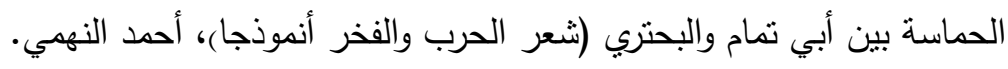




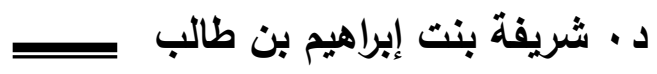

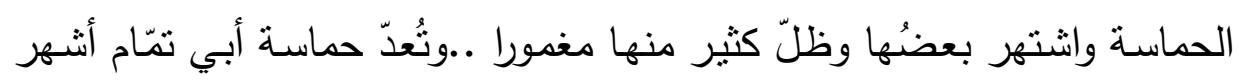
الحماسات بلا منازع.

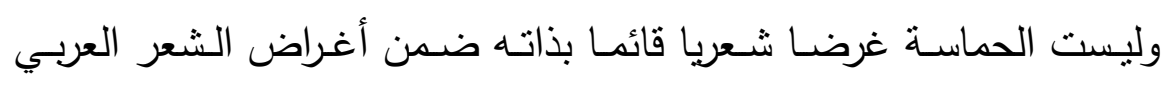

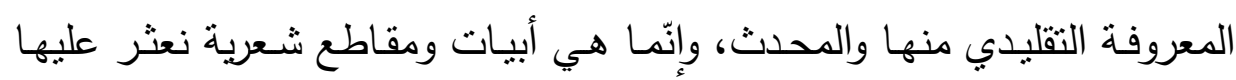

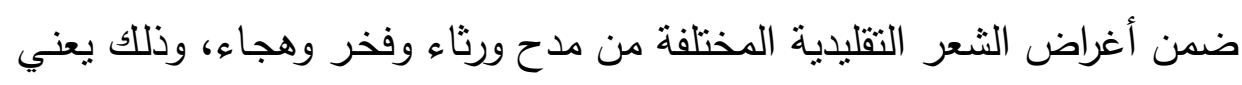

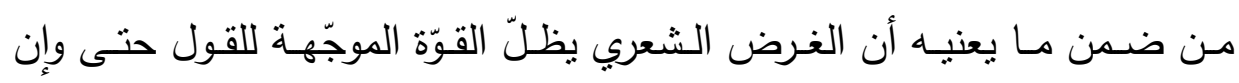

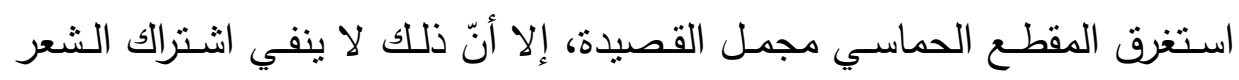

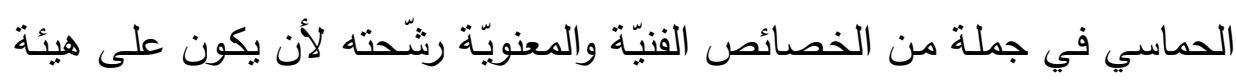

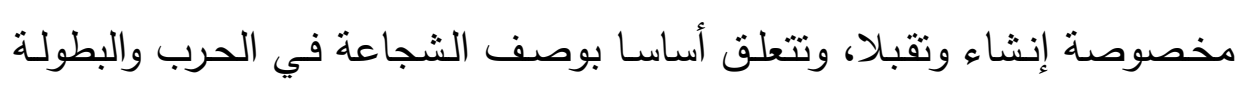
فيها وتتخنى بخصال القادة ومآثرهم وتمجّد إنجازاتهم العسكرية (1).

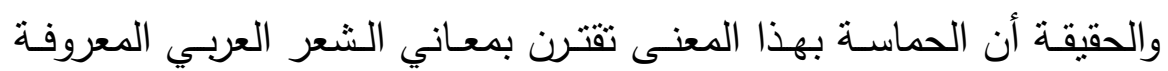

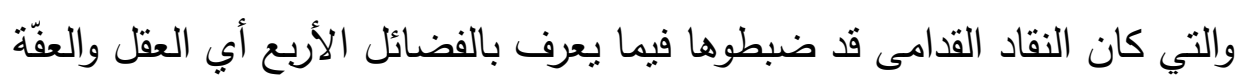

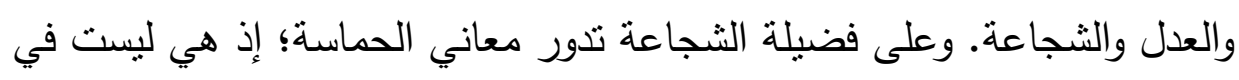

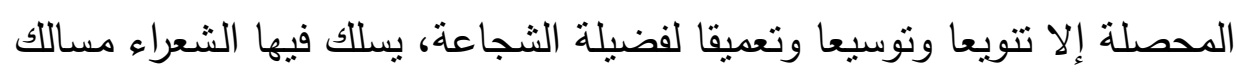

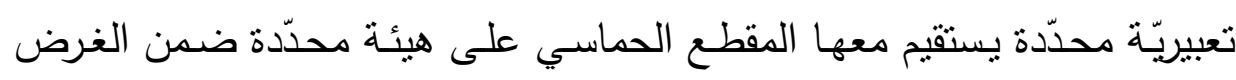

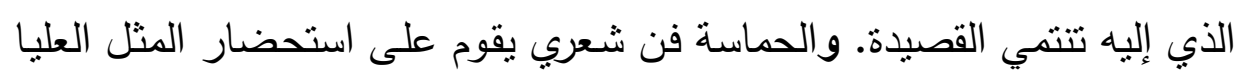

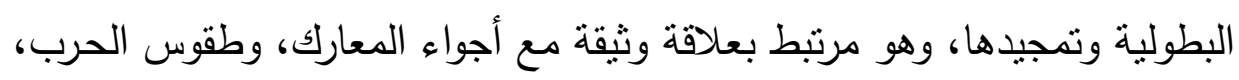

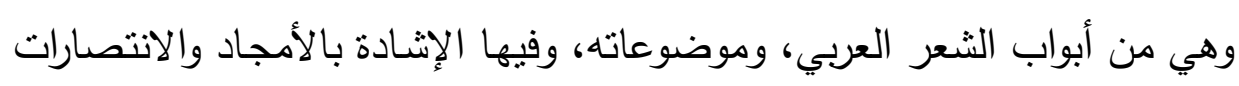

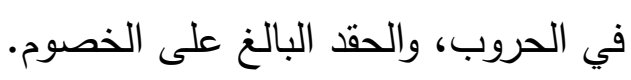
يمتاز شعر الحماسة بشكلٍ عامّ بعدة خصائص منها: المبالغة في الاقتخار ، ولئل

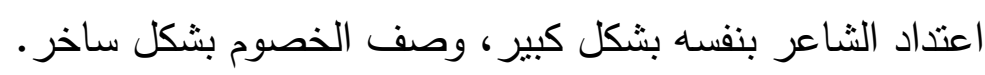

(1) الظرر : الخصائص الأسلوبية في شعر الحماسة بين أبي تمام والبحتري (شعر الحرب

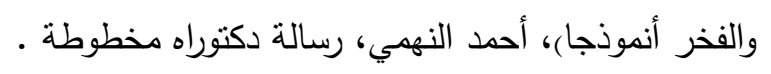




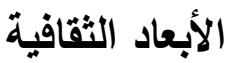

وتطور شعر الحماسة على امتداد عصور الأدب، وقوي وضعف بما استجد

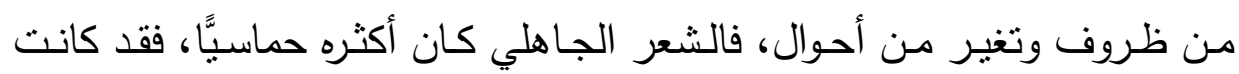

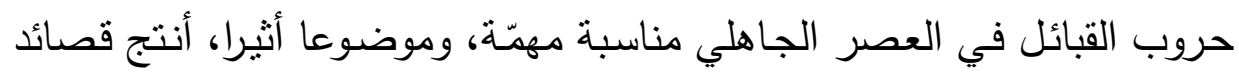

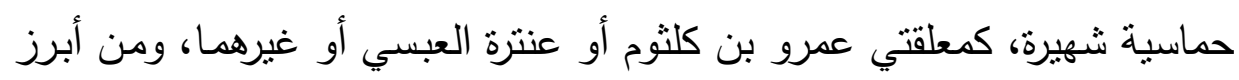

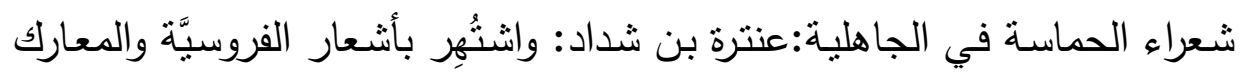

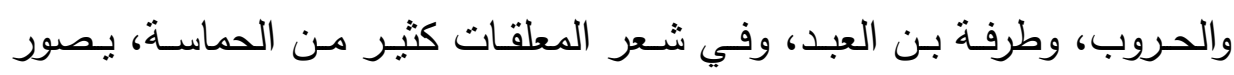
المعارك ويحمس الأبطال، ويثتبتهم في ميادين القتال.

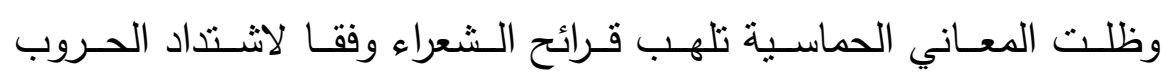
والمواجهات في البلاد الإسلامية، وما يراققه من إعلاء منزلة الجهاد في سبيل

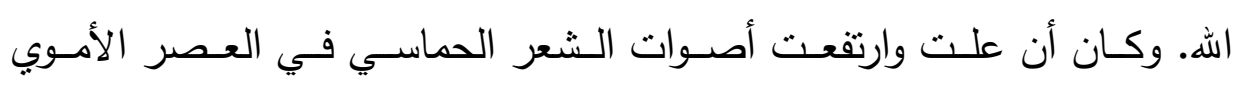

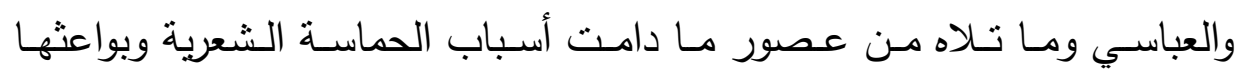
وجمهورها والوظائف المناطة بها قائمة.

والقصائد الحماسية كانت بمثابة الوقود لمشاعر المحاربين، تدفعهم إلى البذل

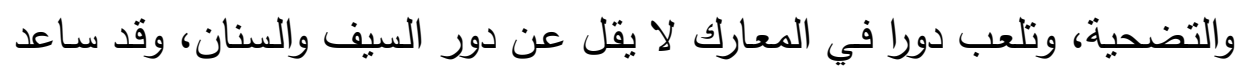
على ازدهار الشعر الحماسي في العصر الجاهلي، طبيعة البيئة البدوية القاسية

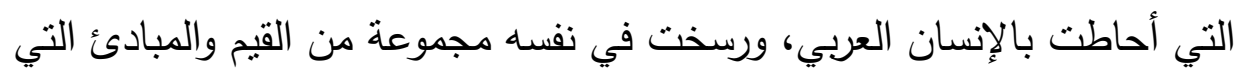
تحث في مجملها على الثجاعة والجود والفروسية والحرب الحرية والكرامة والنجدة والتضحية.

ثم جاءت رسالة الإسـام ترسم للعرب مثناً عليا جديدة في التشريع وسائر

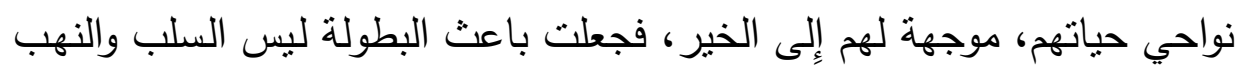

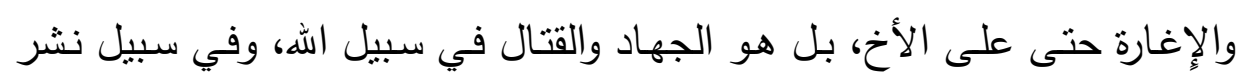

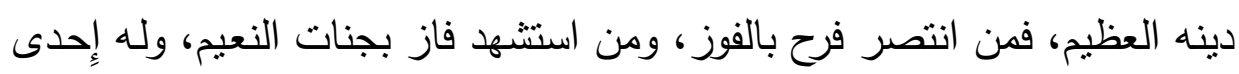
الحسنيين، فازدهر شعر الحماسة الدينية وشعر الجهاد. 


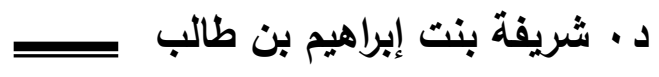

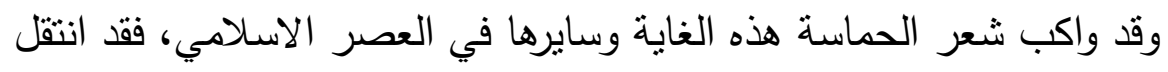

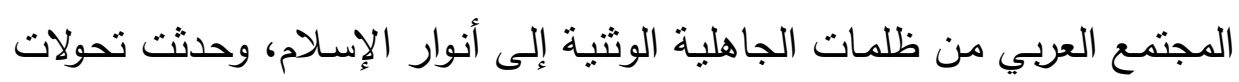

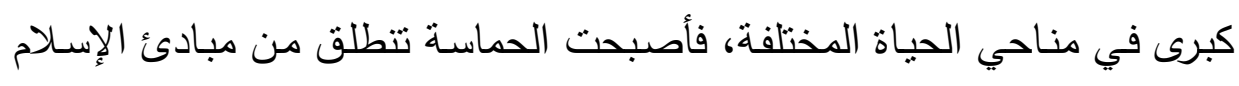

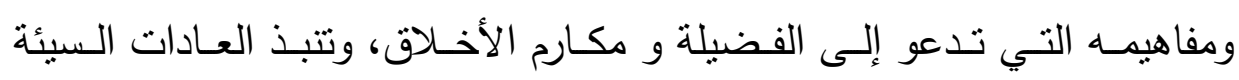

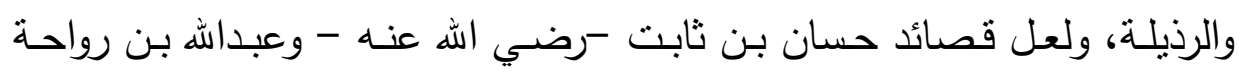
وكعب ابن زهير خير ما يمنل شعر الحماسة.

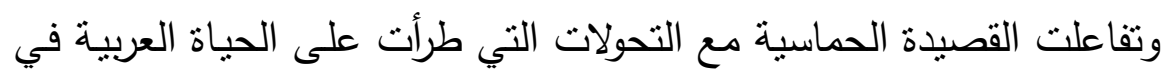

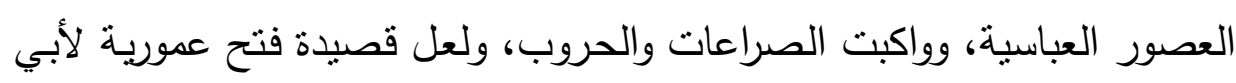

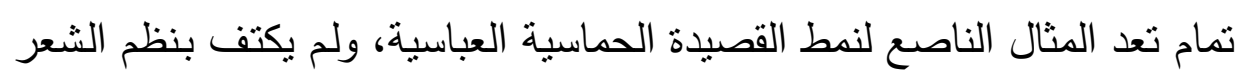

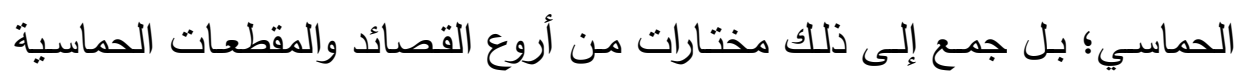

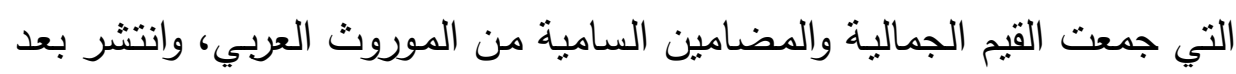
ذللك التأليف وجمع الحماسات.

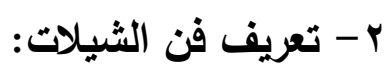

فن الثيلات فن شعبي شعري ملحون، وهو فن مستحدث، تصاحبه إيقاعات

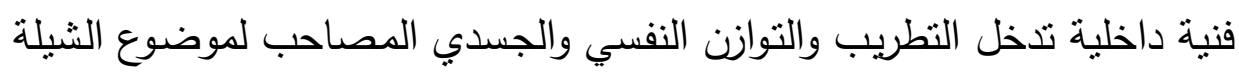

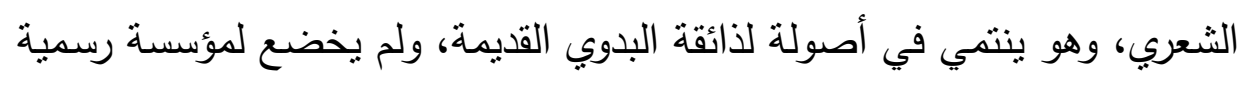

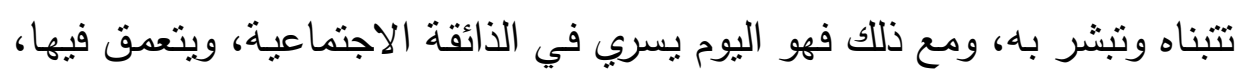

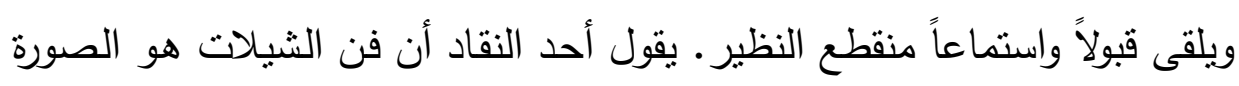

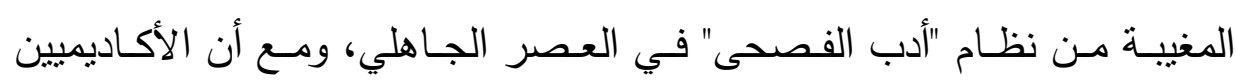

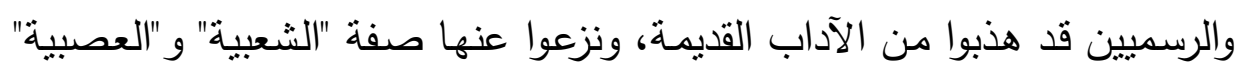
ليجعلوه أدباً "راقياً،ساميا،ذا هدف في في الحياة" كما يسمون ذلك، إلا أن "النظسام

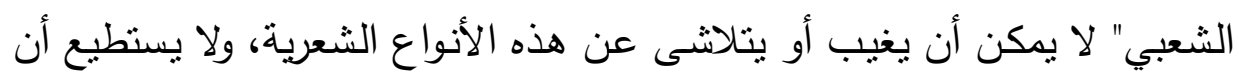


يكون مقنناً أو مهذباً، بل هو صورة لانكثافات الطبيعة البشرية وتفاعلاتها مع كل قضايا الحياة' (') والثيلة مأخوذة من رفع الثيء والعلو به، فالعامة تقول "ثيلوها "يعني ارتقعوا

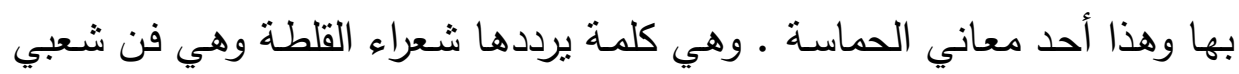

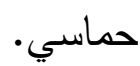

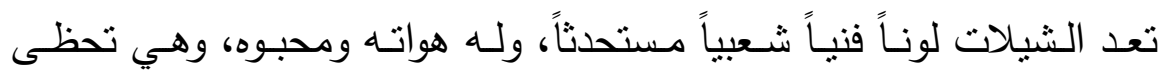

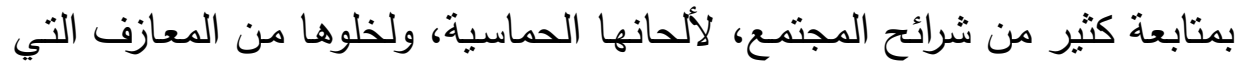

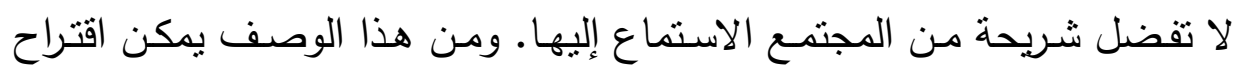

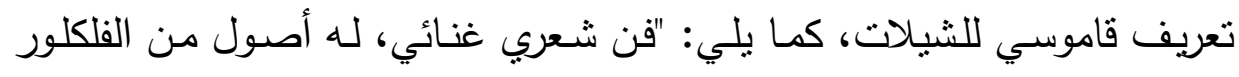

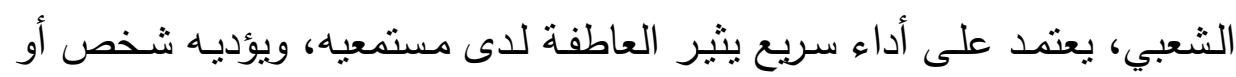

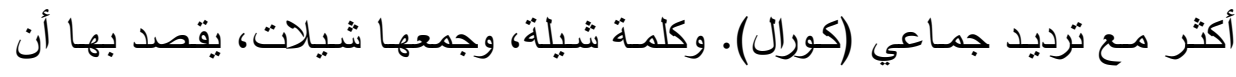

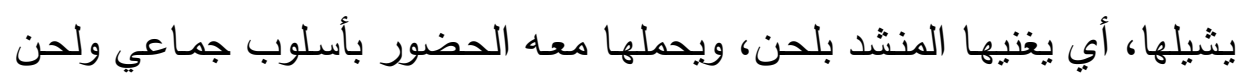
غنائي

تتسم الثيلات بسمات أساسية تفصلها عن الأغنية، مثل: أن لغتها عامية،

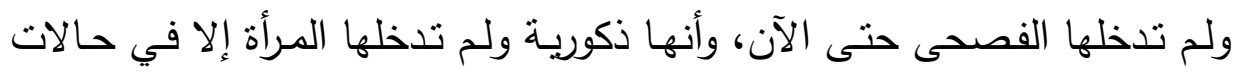

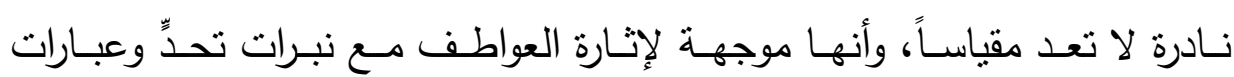
تصادمية تمنل الدفاع عن القبيلة والوطن أو تؤكد عناصر القوة والنفوذ في مدائح

( (1) انظر :مقال على الثبكة الإلكترونية، بعنوان: من أين جاءت الثيلات ؟، سمير الضامر ،

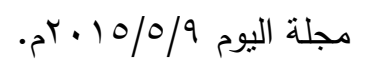

https://lym.news/a/1 . . ^^^r

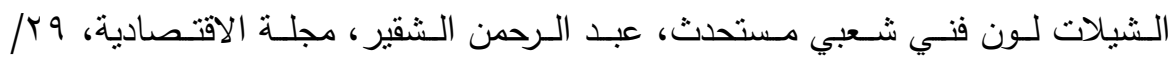

$$
\text { مارس / } 9 \text { أ. rم مقال إلكتروني. }
$$

https://www.aleqt.com/r.19/.r/ $/$ q/article_lov . .01.html 


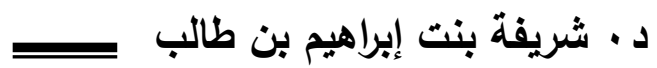

الشخصيات، ولم تدخلها المشاعر والعقلانية إلا بحدود ضيقة. وهذا يدعم فكرة أنها صنعة اقتصادية ممولة، كما اتهمها كثير من النقاد.

وتتكون من أربعة عناصر ، هي: أولاً القصيدة، وبلحظ أن القصيدة والثاعر

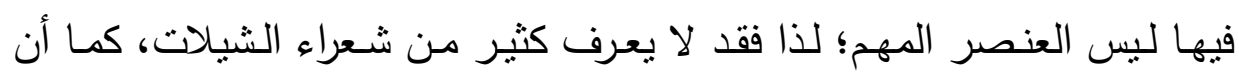
بعضهم لا يذكر اسمه، ويوجد شعراء مغمورون ومشهورون يبيعون القصائد بمبالغ زهيدة. والعنصر الثاني: المنشد الذي يشيل القصيدة بلحن، وتستخدم تقنيات فنية لتحسين الصوت وتفخيمه، مما يسهم في تأثثر الثيلة. والعنصر الثالث: اللحن والإيقاع، وهذه غالباً تكون معدة مسبقاً من مؤسسات الإنتاج، ولا تحتاج إلى ألحان

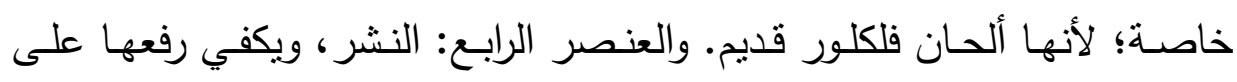
يوتيوب؛ لأنها لا تحتاج إلى موزع وحقوق نشر وملكيـة فكريـة، وهذا من أكبر أسباب ذيوعها ومما أسهم في انتشارها ' '. ويمكن القول أن أكثر الشيلات الضعيفة فنيا كان الدافع منها التكسب وبذلك تحولت الثيلات إلى سوق اقتصادية، وذلك لسهولة إنتاجها وسرعة تنفيذها وبثها، ورخص ثمنها مقابل قوة تأثيرها (r). ومن الباحثين من وصف الشيلات بـافن الصراخه، وأكد أنها تهدد التراث الشعبي وتطغى على الكثير من الفنون الشعبية التي تمثل الهوية الحقيقية للفن،

ونضيف أنها تهدد الشعر بشكل عام أيضا (r). (1) انظر : الشيلات لون فني شعبي مستحدث، عبد الرحمن الشقير، مجلة الاقتصادية، وج/ مارس /9 1 • rم مقال إلكتروني.

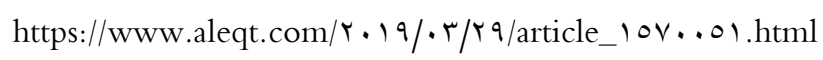

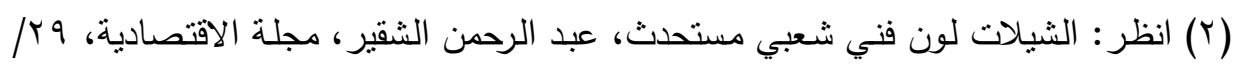
مارس /9 1 • بام مقال إلكتروني. https://www.aleqt.com/ . • 19/. $/ /$ q/article__ov ..01.html

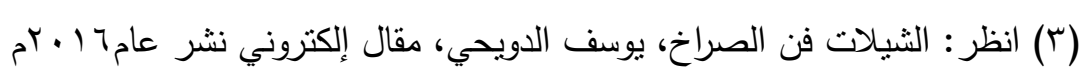


المبحث الثاني

\section{أوجه التثابه والاختلاف}

\section{1 - دواعي ودوافع الحماسة والثيلات:}

من نظرة سريعة في دواعي الحماسة والثيلات نجد اتفاقا في الدوافع ؛ فمن فئن فئاء

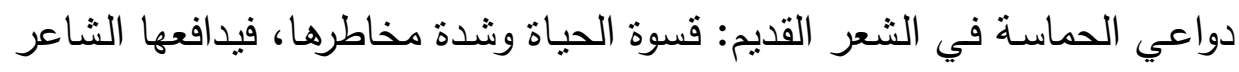

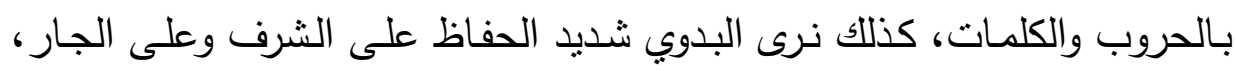

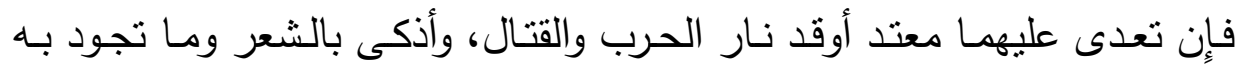

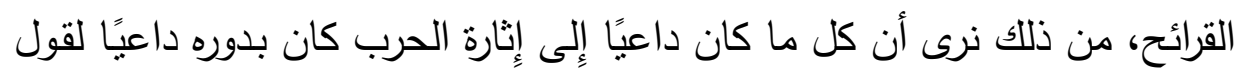

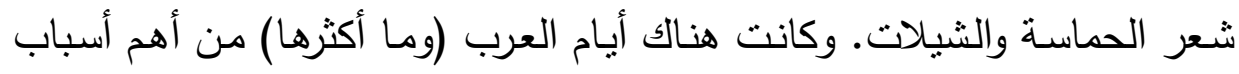

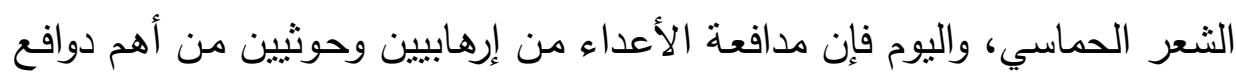
الثيلات . الثنير الحمات

وإِنا نجد أن الأخلاق والعادات التي فخر بها العربي كانت ثمرة ونتاجًا للبيئة التي عاش فيها ومن وحيها فخروا بالثجاعة؛ لأنهم في قسوة الحياة وشدتها عليهم

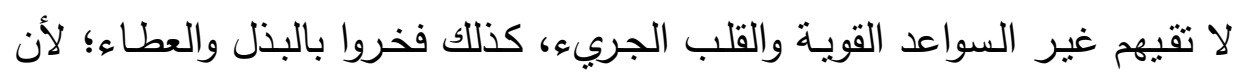

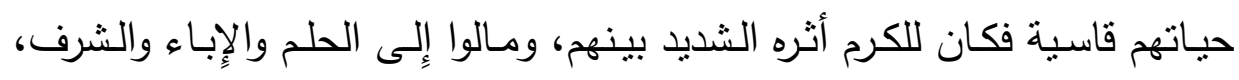
وتغنوا بإِائهم وترفعهم عن الدنايا، وكان الوفاء عندهم من أقدس الأمور نظرًا

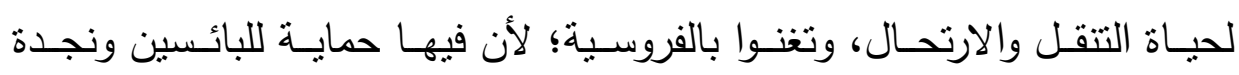
للمستضعفين. من هنا نرى أن البيئة الطبيعية تركت آثارهـا البارزة في ملامسح

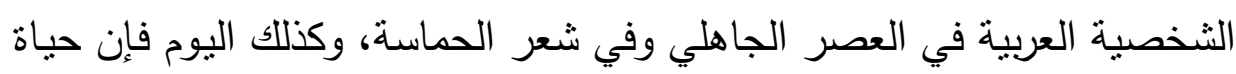
الحروب والنعرات القبلية ومهرجانات الإبل والصقور عززت قيم القيم العربي القديمة وأذكت الثعر ولكن في صورة شعبية . 
د. ش شريفة بنت إبراهيم بن طالب عـــ

r - موضوعات شعر الحماسة وفن الشيلات:

يمكن تقسيم الشعر الحماسي حسب دوافعـه إلىى: شـعر المعـارك، وشـعر

الفخر ، وشعر المدح • لما كانت الحماسة ترجع في معانيها إلى معنى مركزي في الـشعر العربـي هـو الشجاعة أو البـأس، فـإنّ الـشعراء يعمـدون، في المقـاطع الحماسيّة، إلى توسيع هذا المعنى وتقصيله وتوليد معانٍ جديدة ومتتوعة منه. وينتّ ذلك عبر الإحاح على تصوبر المشاهد الحربيّة وإطالة اللوحات الوصفية. أما الثيلات فيمكن تقسيمها بناء على دوافعها إلى: اتجاه مؤقت، وبتمنل في الإهي شـيلات ذات مناسـبات محددة وتتتهي بنهايـة الحدث مثثل: الـشيلات المرافقـة لمهرجانات الإبل، والزواجات، ومدائح أثخاص أسدوا معروفا، وهذا الاتجاه ينتهي

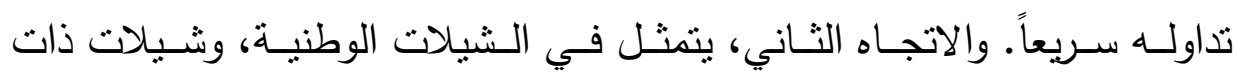
موضوعات اجتماعية وأدبية وتاريخية، وهذا النوع يبقى طويلاً في الذاكرة، وسريع الانتشار وتأثيره قوي، وهي الثيلات التي تعبر عن اللاوعي الشعبي، وهي أيضاً تتقسم إلى شيلات إيجابية تبث قيم الكرم ونجدة المحتاج والمروءة، وشيلات سلبية تبث قيما لا تتقق مع قوانين المجتمع وعاداته والقيم الإسـامية ' .

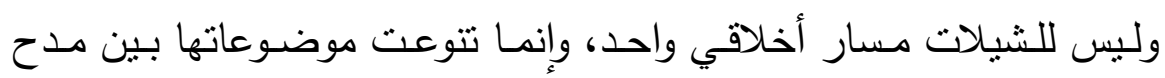
وترحيب وتوثيق مناسبات خاصـة ونصائح دينية ووطنية، إلا أن أكثر الشيلات

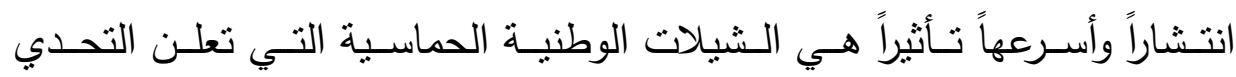

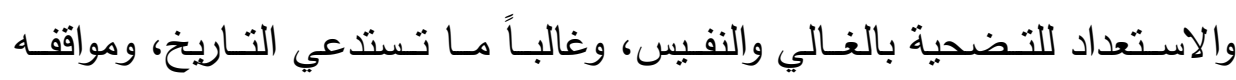
البطولية، ورموزه وأبطاله.

(1) انظـر : الشيلات لون فنـي شعبي مستحدث، عبد الـرحمن الشقير ، مجلـة الاقتصـادية،

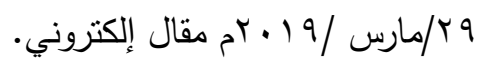
https://www.aleqt.com/r.19/. $/ /$ q/article_lov . .01.html 
وأكثر الثيلات الحماسية أطلقت كوامن اللاوعي في الإنسان، وصارت أداة

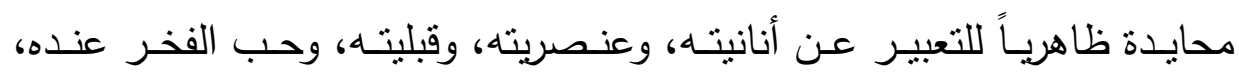

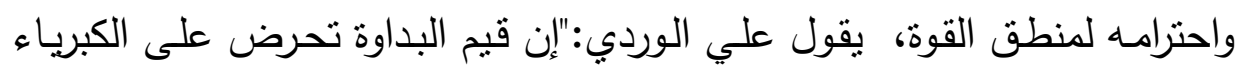

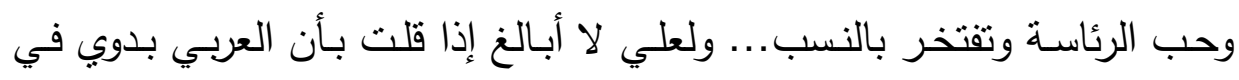
عقله الباطن، مسلم في عقله الظاهر، فهو يمجد القوة والفخار والتعالي في أفعاله، بالها.

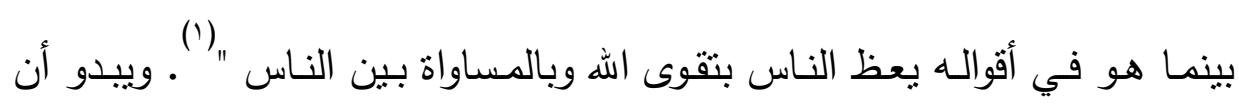

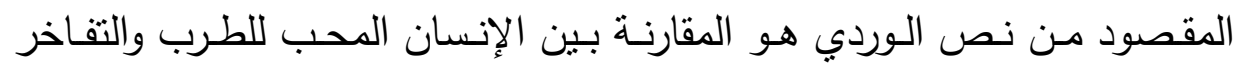

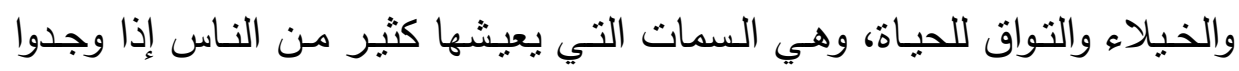

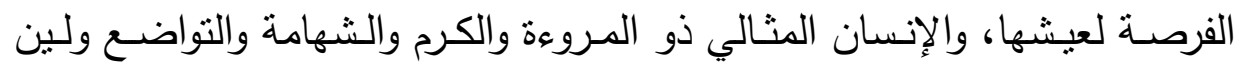

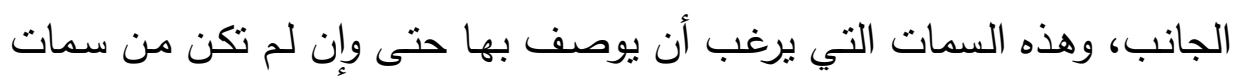
شخصيته. وقد لبت الشيلات هذه الحاجة، فأكثرها كانت في مدح مواقف الرجال الكرام، ومن ذلك شيلة "رجال المواقف "، ومنها:

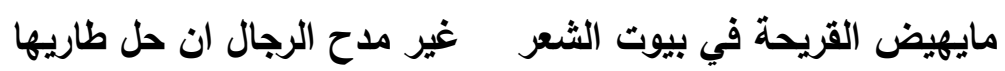

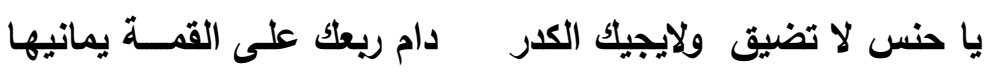

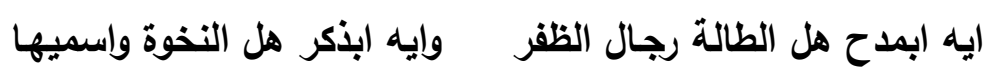
كيف مانفتخر بك ياوريث الفخر وانت كفلك على الجزلة مضريها ومنها:

يشوش راسي على الطاروق وألحانه إذا ذكرت النثاما وزان طاريها

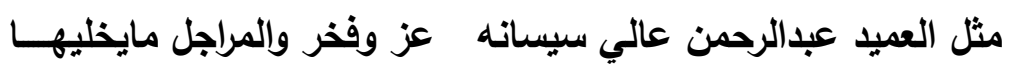

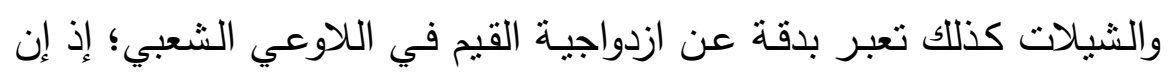

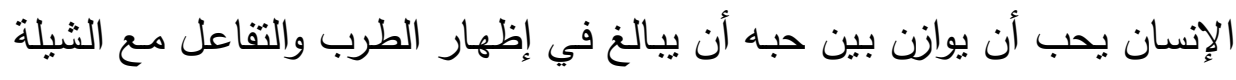

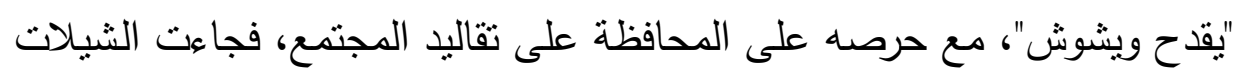

(1) انظر : وعاظ السلاطين، علي الوردي، ص 9 (، مطبعة المعارف، العراق، ؛9 90 م. 


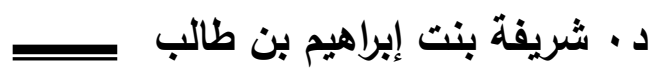

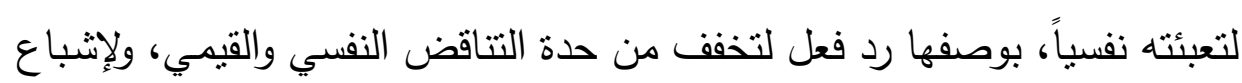

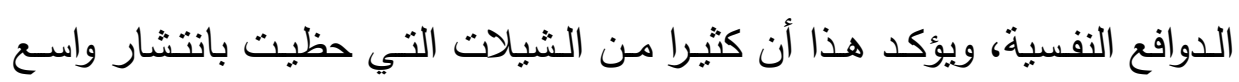
تتضمن عبارات التحدي والصدام. والثشيلات تخبرنا عن حقيقة اللاوعي الشعبي الذي يلجأ للقوة وحب الوجاهة الثة والمال. كما أن محتوى بعض الثيلات تسهم في تضخيم الذات والشعور بالفوقية على الآخرين، خصوصا شيلات القبائل، ومنها شيلة حرب المعروفة بـ "زلزيلة ". ومنها شيلة "عز وفخر":

عز وفخر يامحزمي عز وفخر يا أهل المراجل كلها وأهل الفعول الوافية

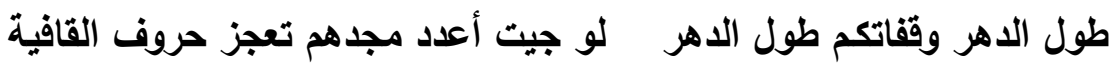
وكثير من الشيلات الحماسية تدور حول ذات المهر المعاني الجاهلية، وتؤجج المشاعر ذاتها. r- مقارنة بين قصائد حماسية وشيلات:

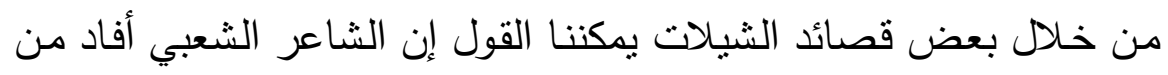

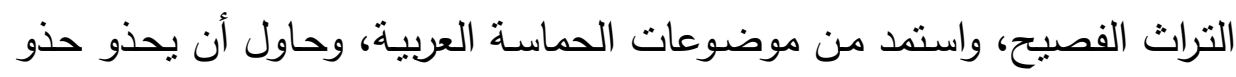

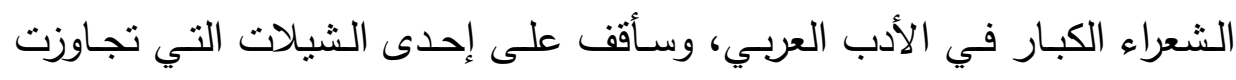

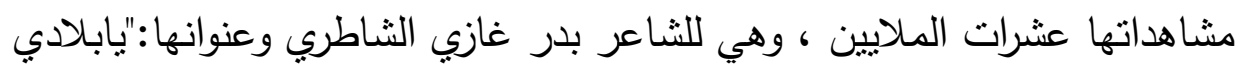

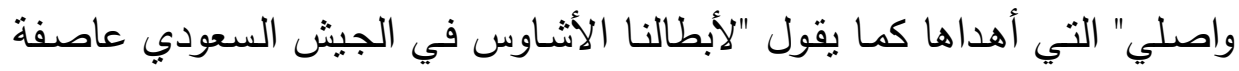
الحزم" وهي من أداء المنشدين: (حاتم الثاطري و حاكم الثيباني") يقول فيها:

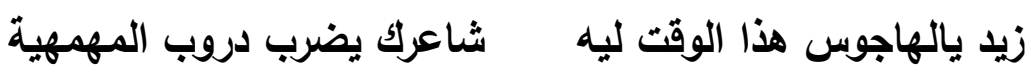

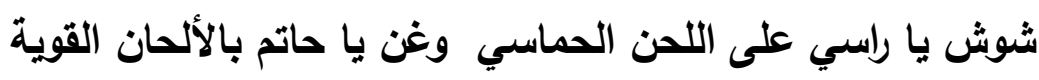
الوطن تنزف على شانه دمانا الثجاعة طبع في النفس الأبية يابلادي واصلي والله معاك كلنا ياموطني لجلك ضحيّه رددي اللهُ أكبر لايهمّك د دينتا الدافع وحبك وإلحميه يابلادي كلنا نحمي ترابك كلنا وأرواحنا لجلك هليّه 
الحروب هي درينا يم المعالي بالفعايل ماطلبناها عطيه غطرفي حنا حماة الدين حناما تركنا لأهلنا غير الوصيّه

مالنا وأنفاسنا وأرواحنا لكطايره في الجو وأرضك مدفعيه في الطلب جيناك في الصف الامامي حزّة يعذر خوي في خويَّه

كلنا كلمة رجل واحد محنّك ضابط الميدان وأفراد السريّه من يعاديك أبشري حنا عدوّه درع ثابت والبنادق في يديّه

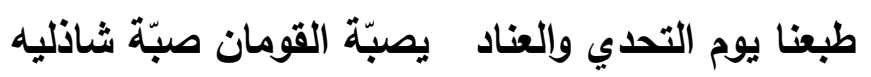

وهذه القصيدة جزلة المعنى، قوية التركيب في موضوعها، والدور الذي أدته

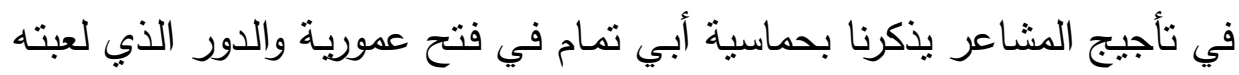
في نفوس الجيش والقادة، وتذكرنا بقصيدة المتنبّي التي منها:

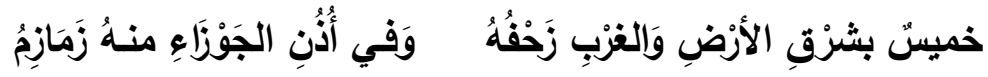

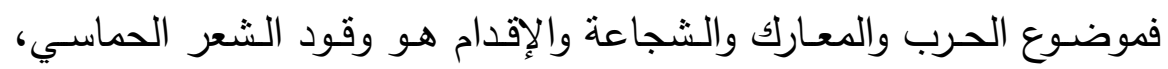

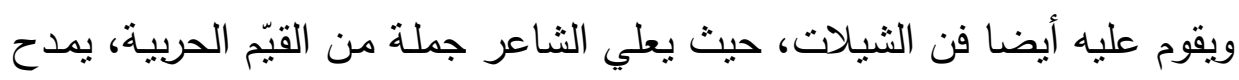
بها ويمجد عظماء قادة الحروب وأبطالها.

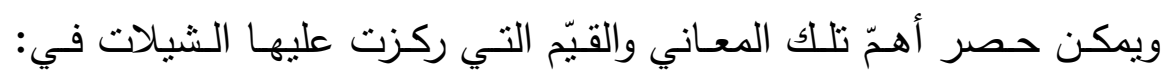

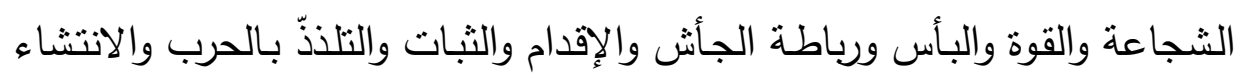
بالوقوف في أخطر مواقعها، وفي هذا المعنى يقول أبو نمام:

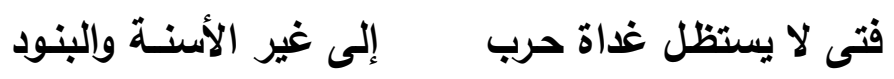
(') أخو الحرب العوان اذا أدارت رحاها بالجنود على الجنود

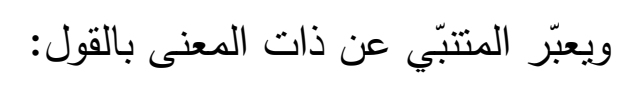

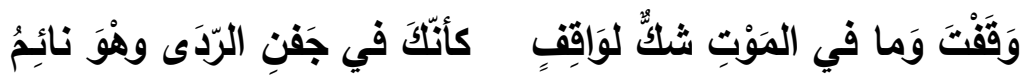

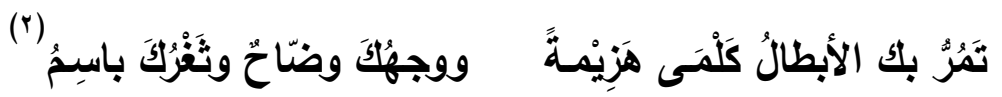




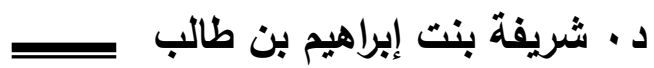

$$
\text { ومن الثيلات التي عبرت عن ذات المعنى شيلة: }
$$

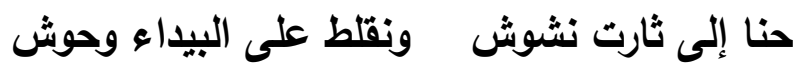

نشرب من الام الحمر كنه فناجيل الدلال

ياكنترول ياكنترول سجل لنا أقوى دخول

ع - القيمة الثقافية لفن الثيلات، وأثرها على الثعر الفصيح:

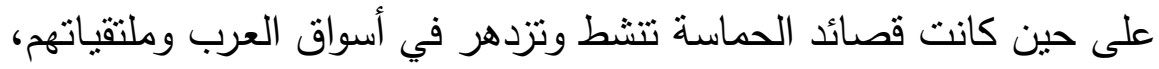

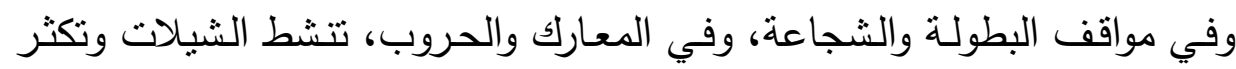

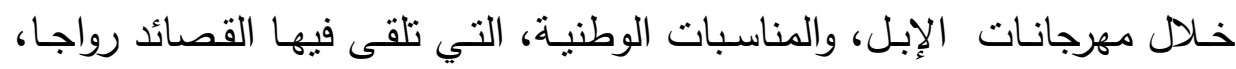
ويتحصل بعض أصحابها على مبالغ مالية، ومكافآت وعطايا مما جعل أكثرها يتحول إلى تجارة وبضاعة رخيصة.

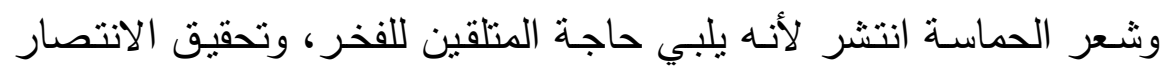

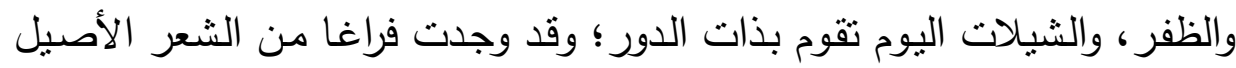

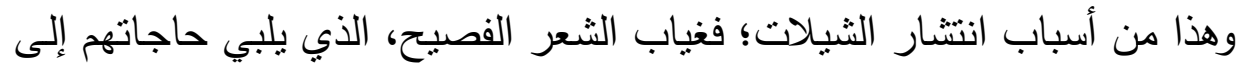

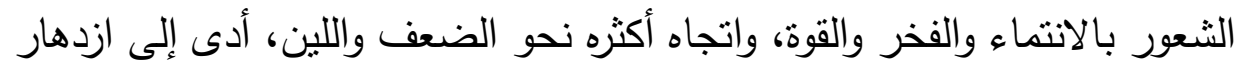

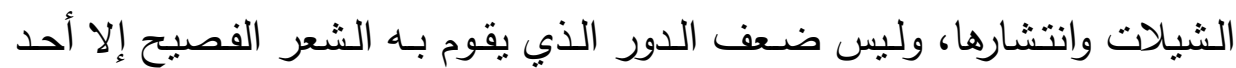

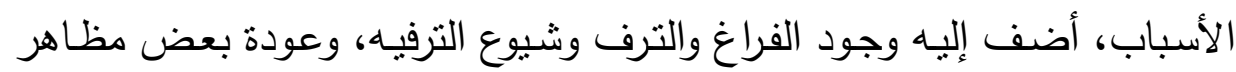

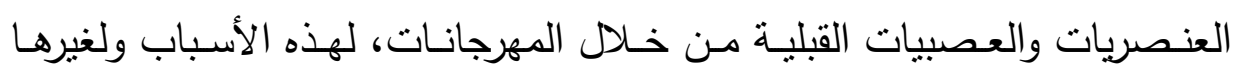

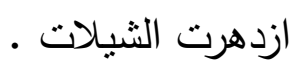

ومما يمكن أن يكون مبررا لانتشار الثيلات ومزاحمتها لباقي الفنون هو قوة

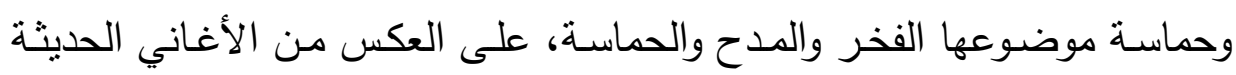

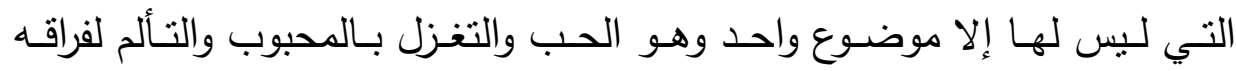
والسعادة بوصاله وانتظار مواعيده... إلخ.

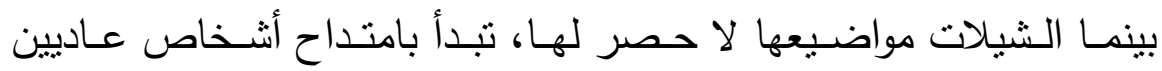

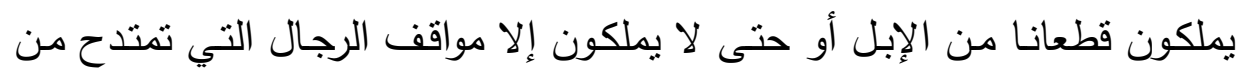


كرم وفزعة، وإعلان الولاء القبلي للوطن الواحد وللحكومة، إلى غرض الحماسـة

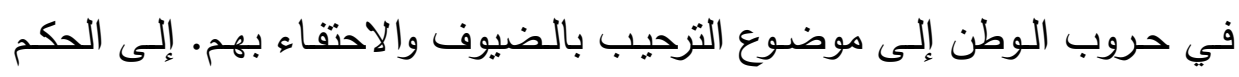

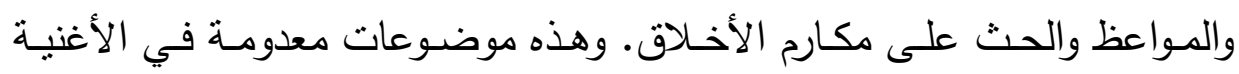
السعودية.

ولئن كانت المعاني الحماسية في أغلبها تقليديـة فإنها تتنزع طرافتها من جمالية الصورة وإحكام البناء وقوة الإيقاع والخروج باللفظ من دائرة الاستخدام

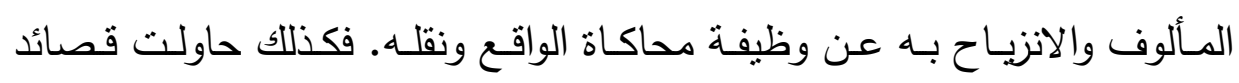

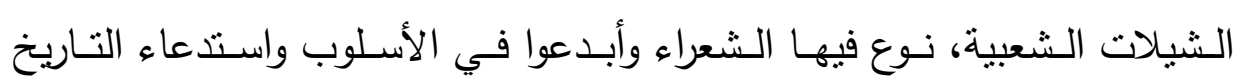

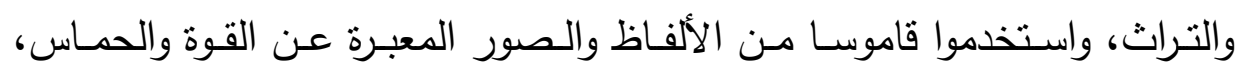

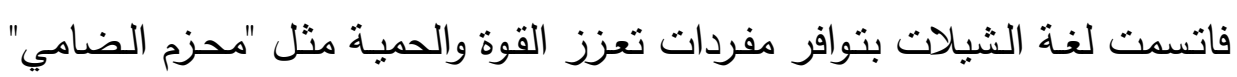

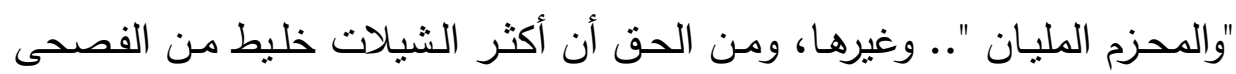
والعامي والثعبي بل والأعجمي أحيانا كما في شيلة "زلزيلة ".

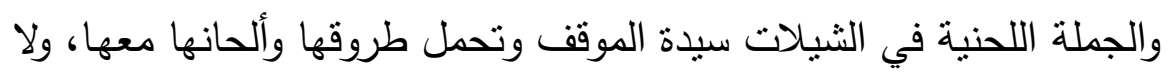

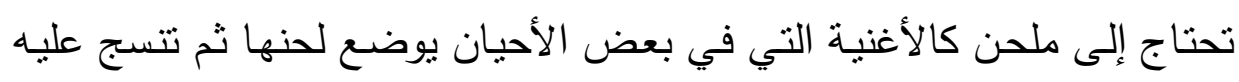

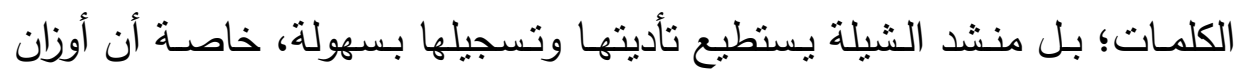

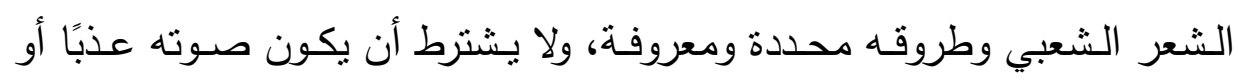

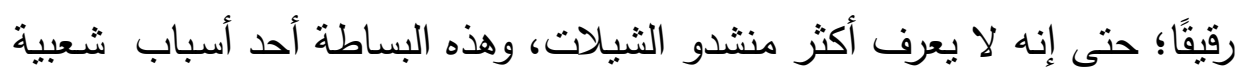
الثيلات وميل الناس إلى سماعها.

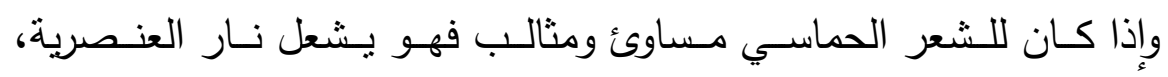

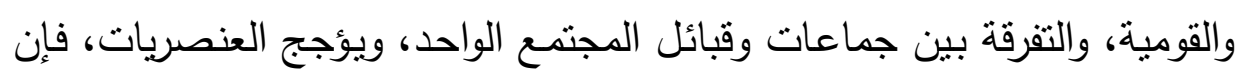

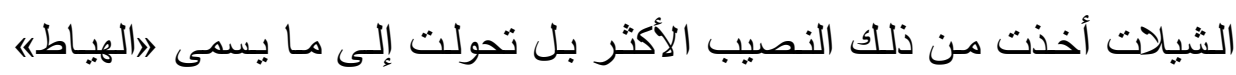

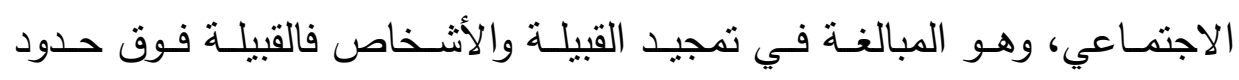

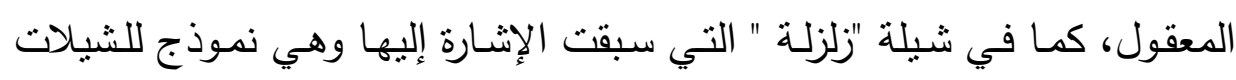




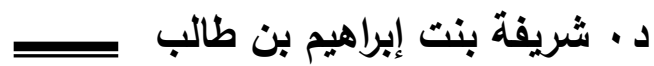

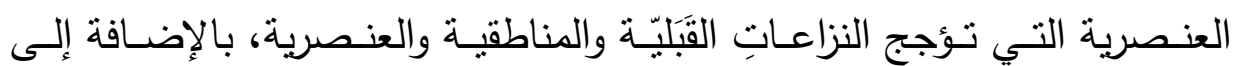
احتوائها على مضامينَ فيها تَسطيح للمجتمع.

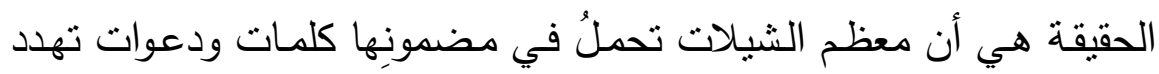

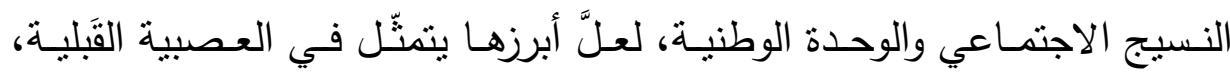
والتفاخر بالأحساب، ورفع شعارات جاهلية، والتغنّي ببطولات الآباء والأجداد.

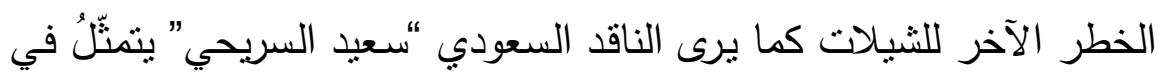

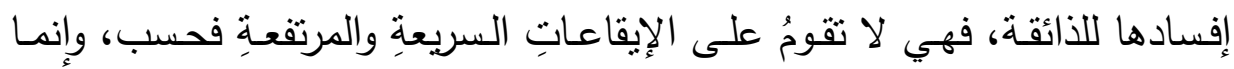

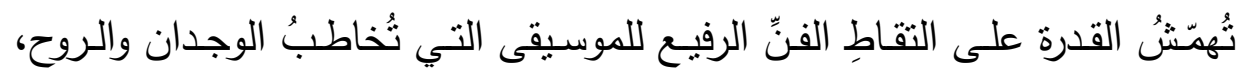

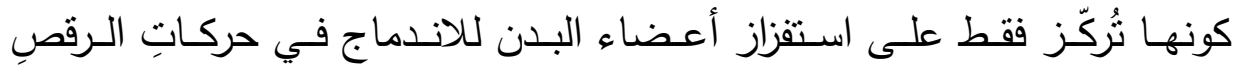

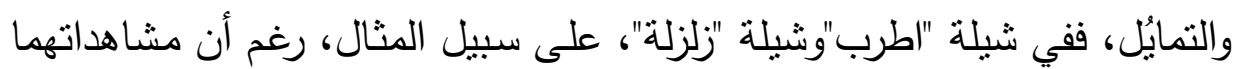
على يوتيوب بلغت عشرات الملايـين، إلا أنـك لا تكـاد تفهم كلماتها، لطغيـان الإيقاع السريع عليها. ثم يبرر لذلك بالفوضس التي تعيشها فن الشيلات، وغياب الرقيب، وهما

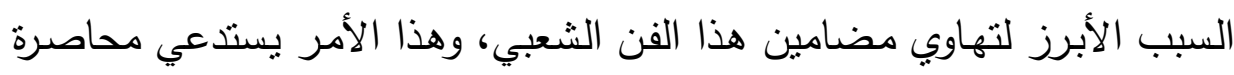

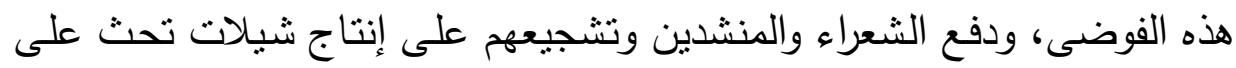

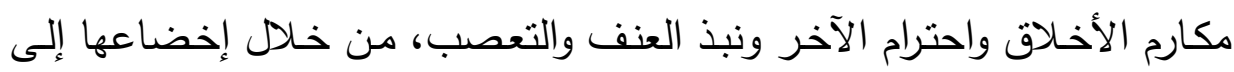

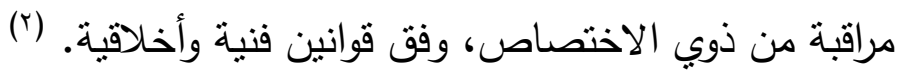

( (1) انظر : الشيلات لون فني شعبي مستحدث، عبد الرحمن الشقير ، مجلـة الاقتصادية،

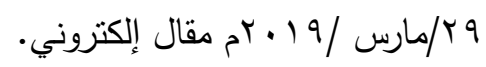
https://www.aleqt.com/r.19/.r/rq/article_l ov ..01.html (r) انظر : الشيلات.. بابٌ جديدّ للإبداع أم عنصرية وإفساد للائقة ؟عمر الهاثمي، مقال إلكتروني (الفز 
حاولت في هذه الدراسـة التوصل إلى العلاقـة بين فن الشيلات الشعبي،

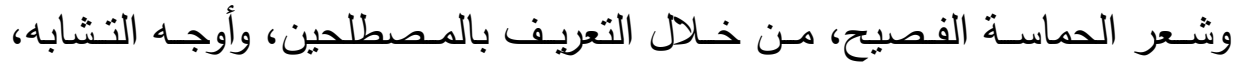

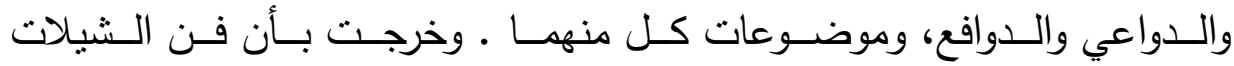
على صـورته المعروفـة والمنتشرة اليوم قد يكون هو النـوذج المغيب للشعر الفصيح وعلى الرغم من البون الثاسع بينه وبين شعر الحماسة في اللغة، والأسلوب،

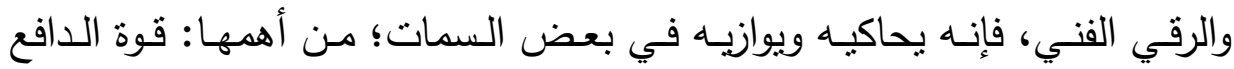

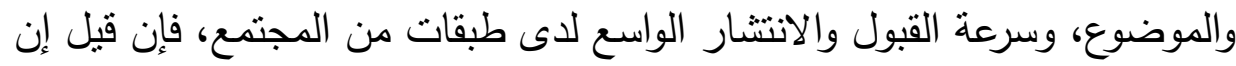
موضوع الحماسة في القرون الأولى طغى على كل موضوع فإن الثيلات اليوم كذلك، وهما يتشاركان في الموضوع والدوافع والأسباب والمؤثرات، مما يؤكد مقولة أن الثيلات قامت بدور الثُعر الفصيح المغيب في هذا الزمان .

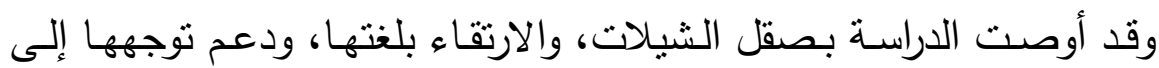

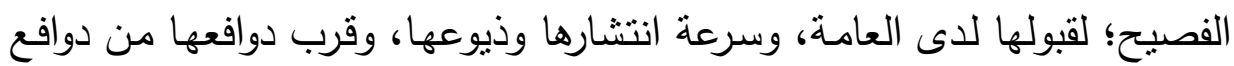

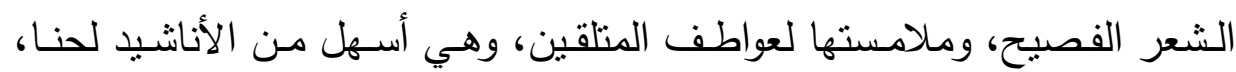

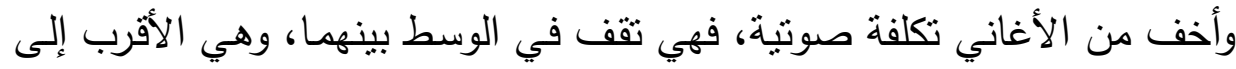

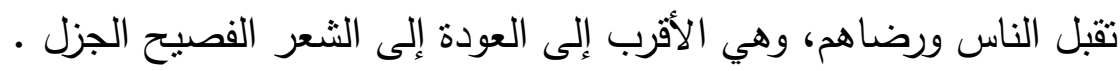

